\title{
PAISAJE CULTURAL Y VIALIDAD EN LA PUNA DEL EXTREMO NORTE DE CHILE: EL CASO DEL ASENTAMIENTO PUEBLO VIEJO DE PARINACOTA Y SU CONEXIÓN CON ASENTAMIENTOS CARANGAS E INCA AL OTRO LADO DE LA CORDILLERA ${ }^{1}$
}

\author{
CULTURAL LANDSCAPE AND ROAD NETWORK IN THE PUNA OF \\ NORTHERNMOST CHILE: THE CASE OF THE PUEBLO VIEJO DE \\ PARINACOTA SETTLEMENT AND ITS CONNECTION TO CARANGAS AND INCA \\ SETTLEMENTS ACROSS THE ANDES MOUNTAINS
}

Iván Muñoz ${ }^{2}$

\begin{abstract}
Los estudios desarrollados en la puna del extremo norte de Chile señalan que Pueblo Viejo de Parinacota correspondería al asentamiento de mayor altura $-4.300 \mathrm{msm}$ - construido por pastores vinculados a las poblaciones Carangas, aproximadamente en el año 1400 DC. Eligieron el lugar de asentamiento a los pies de los nevados Payachatas, aprovechando las potencialidades que les proveía el Bofedal de Parinacota y la majestuosidad como ente protector que le ofrecían los nevados. Constituyó un espacio de articulación en las cuales se integraron redes viales que conectan distintos lugares y asentamientos humanos de la puna chilena, como los tambos y bofedales de Caquena, Tacora y Chungará, y también del altiplano central boliviano, como Caquiaviri, Turko, Sabaya, entre otros.
\end{abstract}

Palabras claves: Asentamiento, pastores, poblaciones Carangas, bofedal, redes viales, Nevados de Payachatas.

Studies carried out in the northernmost part of Chile's puna indicate that Pueblo Viejo de Parinacota would be the highest settlement - 4,300 masl - built by shepherds linked to the Carangas populations approximately in 1,400 AD. They chose the foot of the Nevados de Payachatas as a place of settlement, harnessing the potential of the Parinacota wetlands and using the magnificence of the snow peaks as a protective entity. Pueblo Viejo de Parinacota established as a space of articulation, where road networks integrated, connecting different places and human settlements of the Chilean puna, like the tambos and wetlands of Caquena, Tacora, and Chungara, and those of the Bolivian central Altiplano as well, such as Caquiaviri, Turko, and Sabaya, among others.

Key words: Settlement, shepherds, populations Carangas, bofedal, road networks, Nevados de Payachatas.

Los senderos hallados a raíz de una extensa prospección arqueológica en el tramo Visviri-Parinacota poseyeron y poseen importancia en la unificación vial de dos ecosistemas, el Bofedal de Chungará, Cotacotani y Parinacota por el sur y el Bofedal de Caquena por el norte, los que constituyeron dos polos importantes de desarrollo en materias económicas, políticas y sociales generadas en la puna durante el periodo Tardío Precolombino, para continuar durante los periodos Colonial y republicano.

Debido a la superficie plana del territorio donde se trazaron los senderos no se observa un trabajo como en la precordillera o sierra de Arica, donde hay evidencias de ensanchamiento de los senderos, empedrado de las entradas y salidas de los poblados, como Socoroma, Zapahuira y Belén. Tampoco hay construcción de muros laterales de los caminos, nivelación o cimientos de sectores con pendiente. En la puna las rutas se desplazan por un terreno plano con escasas elevaciones de cerros, en su superficie presentan una cubierta de pastizales, vegetación característica de ambientes de altura. En su eje cardinal sur-este se observan los Payachatas, nevados tutelares, ordenadores del espacio andino en el contexto de la cosmovisión de los pueblos aymaras.

Junto a los senderos, uno de los rasgos más característicos de las poblaciones prehispánicas tardías

\footnotetext{
${ }^{1}$ Una primera versión de este trabajo fue presentada en el Qhapaq Ñan II, Taller Internacional en torno al Sistema Vial Inkaico (24-27 de octubre de 2017), efectuado en Salta, Argentina. Este manuscrito fue evaluado por pares externos y editado por el Comité Editorial de Chungara y los editores invitados Carlos González y Christian Vitry.

${ }^{2}$ Departamento de Antropología, Universidad de Tarapacá, Arica, Chile. imunoz@uta.cl
} 
en los altos de Arica (sobre $3.000 \mathrm{msm}$ ) son los patrones habitacionales, emplazamientos que se ubican en la cima, a media ladera o faldeos de relieves cordilleranos o "cerros islas". Sus recintos fueron construidos con muros conformados por una o dos hileras de piedras de forma oval y/o circular; éstos, en gran medida presentan evidencias de ocupación doméstica hallándose restos de alimentos, fogones y espacios "de estar".

En el caso específico de la puna, las construcciones prehispánicas tardías reconocidas y estudiadas por Muñoz y Chacama (2006) corresponden a los tambos de Pisarata, ubicado en la localidad de Caquena, Chungará en la localidad del mismo nombre y Ankara en el sector de Tacora, además de chullpas y recintos habitacionales que se hallan en la puna de la comuna General Lagos de la XV Región, norte de Chile (Figuras 1 y 2). Dichos tambos se caracterizan por una estructura edificada de forma rectangular, construida en piedra de doble muros, rellenados con material de grava en su interior. Algunas de estas construcciones presentan en sus paredes hornacinas, otras fueron enlucidas utilizando una argamasa de barro. En lo arquitectónico constituyen las evidencias más claras en torno a la presencia Inca en los ambientes cordilleranos del altiplano chileno. Desde el punto de su espacialidad se construyeron cercanos a bofedales. Según Muñoz y Chacama (2006), su función al parecer estuvo ligada al control de estos espacios, además de servir de albergue a caravanas que se desplazaban por el altiplano.

Un asentamiento mayor en relación con los tambos descritos en el párrafo anterior corresponde al poblado Pueblo Viejo de Parinacota (Pa-2), ubicado cronológicamente durante el periodo Tardío. Los rasgos arquitectónicos que caracterizan la ruina y los fragmentos de cerámicas hallados en superficie reconocen que los habitantes de este poblado estarían vinculados a las poblaciones Carangas. En el asentamiento observamos una estrecha relación con su entorno físico, específicamente con el Bofedal de Parinacota y los Nevados Pomerape y Parinacota conocidos por la comunidad aymara como Payachatas, que significa mellizos.

De lo anteriormente planteado, el presente artículo tiene como objetivo describir en primer lugar un extenso trazado de aproximadamente 70 $\mathrm{km}$ de camino que comunica los poblados de Visviri con Parinacota, su relación con los bofedales y nevados que conforman su entorno y la presencia de pequeños asentamientos prehispánicos que se hallan en distintos lugares donde se desplaza el camino. En segundo lugar describir y discutir el comportamiento de las poblaciones que habitaron el poblado Pueblo Viejo de Parinacota (Pa-2), resaltando la vinculación espacial del poblado con el paisaje y las relaciones que habría establecido la comunidad local con los Inca.
Desde el punto de vista metodológico el artículo se estructura sobre la base de una descripción de los senderos que comunican los poblados de Visviri con Parinacota, así como el sistema constructivo que caracteriza el poblado Pueblo Viejo de Parinacota (Pa-2), junto a los contextos alfareros, indicador más representativo de la cultura material de estas poblaciones. Se suman a esta descripción, los fechados de dos fragmentos de cerámicas obtenidos a través del método de termoluminiscencia. Esta información sumada a los antecedentes bibliográficos sobre investigaciones desarrolladas en el altiplano del extremo norte de Chile y altiplano central de Bolivia fueron fundamentales para el análisis de las conclusiones, donde se destaca la importancia de las redes viales en el altiplano y la edificación del poblado Pueblo Viejo de Parinacota (Pa-2) en el contexto del poblamiento humano en la puna durante el periodo Prehispánico Tardío.

\section{Paisaje cultural}

Thomas (2010) define el paisaje como un conjunto de relaciones dinámicas entre tierra, lugares, personas y materia. Anschuetz et al. (2001), por su parte, señalan que los paisajes son construcciones dinámicas en las que cada comunidad impone y materializa su propio mapa cognitivo de un mundo antropogénico e interconectado, de morfología, planificación y significado coherente. Desde la perspectiva de la memoria, Tilley (2008) plantea que los paisajes entretejen personas, memorias, estructuras, historias, mitos y símbolos, donde la existencia y naturaleza del tiempo y del espacio dependen de la existencia y naturaleza de un sujeto perceptor.

El paisaje se estructura en la interrelación de actores en una red ocupacional que se desenvuelve en tres niveles y donde cada uno configura una determinada dimensión significativa: el espacio físico natural y la dinámica medioambiental con la cual interaccionan los grupos humanos; el espacio social o medio construido culturalmente, donde se materializan las relaciones de poder e identidad entre individuos y grupos; y el espacio pensado o medio simbólico, que permite a través del lenguaje tanto ordenar y dar sentido y significado a la apropiación y control humano de la naturaleza, como también del grupo y la socialización de nuevos sujetos (Ashmore 2010).

En el caso de la puna, algunas evidencias materiales que marcan una profunda relación del hombre con el paisaje son los registros caravaneros como apachetas y markas que, según Duffait (2012: 621): "constituirían los elementos mediadores que conectan las vías con las entidades sagradas del paisaje como los volcanes, cerros y nevados". Estos trazados contactaron y relacionaron una infinidad de puntos del paisaje de puna característico de esta región del extremo norte de Chile, demostrándonos el grado de eficiencia alcanzado por la actividad, como también el conocimiento del medio por el cual esa actividad se desarrolló. 


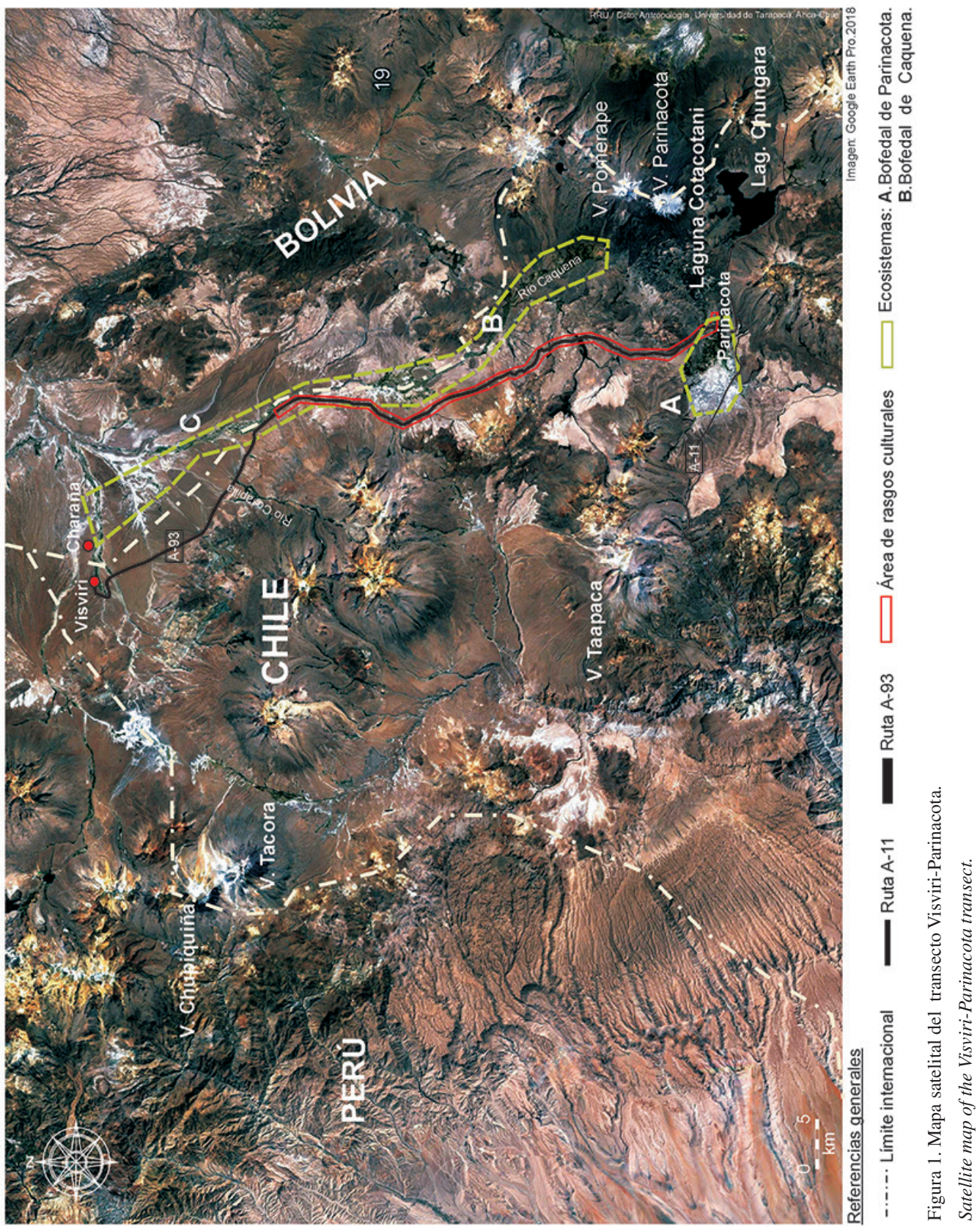




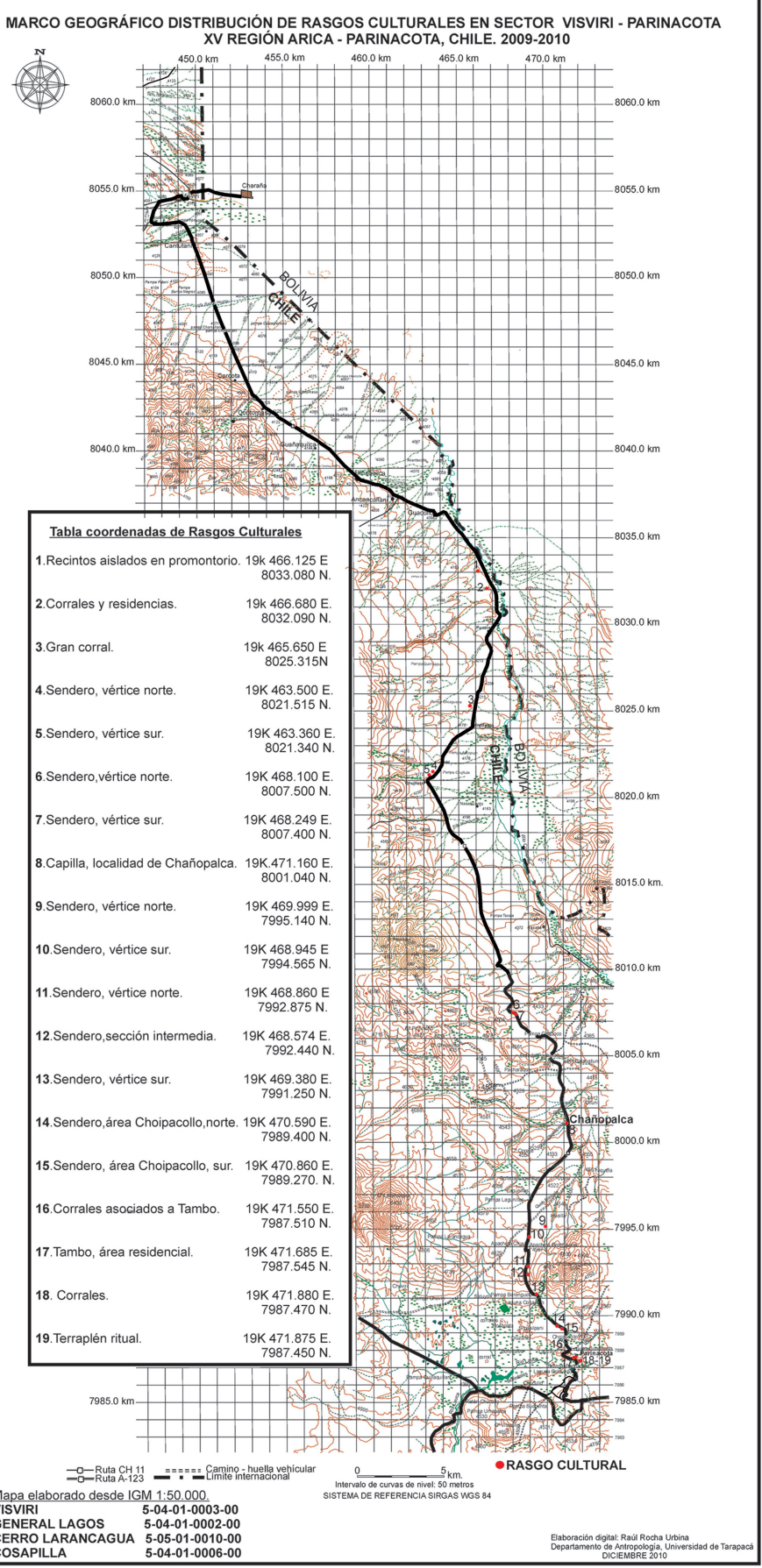

Figura 2. Mapa prospección localidad: Visviri - Parinacota.

Visviri - Parinacota prospecting map. 
Junto al trazado vial se hallan una serie de poblados distantes unos de otros cuya actividad económica giró en torno a la ganadería. Se trata de un territorio que denota mucha importancia por sus apus, cerros guardianes como el Sajama, Tata Sabaya, los Payachatas, Guallatire, entre otros, los cuales riegan los bofedales y ríos con las aguas de sus nevados, permitiendo la existencia de espacios donde se concentra la flora y fauna y, por lo tanto, lugares fundamentales para la actividad antrópica de caza, recolección y pastoreo. La importancia de esta última actividad económica se manifiesta en la naturaleza pastoril de su población, cuya ocupación según Medinaceli (2010) fue dispersa y móvil.

Sobre la importancia de caminos directamente relacionados con el pueblo de indios de Parinacota es interesante señalar un informe realizado en el año 1787 por el presbítero Mariano Pacheco de Peñaloza, cura propio y vicario de la Doctrina de Belén en los Altos de Arica, quien al realizar la demarcación de dicha doctrina señala la existencia de cuatro caminos reales llamados "Potoci", "Cierra", "Carangas" y "La Paz"; y tres caminos locales: "Choquelimpie", "Parinacota" y "Guallatire" (Choque y Muñoz 2016:74). En relación con el antiguo asiento minero de Choquelimpe, se identificaron dos caminos locales, por el norte el "Camino de Parinacota" y por el sur el "Camino de Guallatiri". En el anexo de Parinacota se localiza el cuarto camino real, ubicado en su límite norte, siendo llamado "Camino Real de La Paz" a distancia de dos leguas del mencionado pueblo de indios. El hecho que uno de los caminos reales se haya trazado cercano al pueblo de Indios de Parinacota reafirma la importancia que llegó a tener este poblado en materias de circulación de mercancías e interacciones culturales.

Respecto de la población que ocupó estos territorios, la documentación etnohistórica del siglo XVI señala a las poblaciones Carangas (Bouysse-Cassagne 1987), cuya distribución territorial abarcaba parte de los Departamentos de Oruro, Potosí y La Pazen Bolivia, registrándose también su presencia en los valles del extremo norte de Chile donde poseían enclaves productivos de maíz (Bouysse-Cassagne yChacama 2012; Durstone Hidalgo 1997; Kesseli y Pärsinnen 2005). Uno de los rasgos arquitectónicos que caracterizan a estas poblaciones altoandinas son sus monumentos mortuorios (chullpas), siendo las más relevantes las chullpas de color de la época inca que se edificaron en la región del Río Lauca (Bolivia). Durante la influencia Inca los principales centros Carangas estaban ubicados en Qolqemarka, Andamarka, Huayllamarka, Sabaya, Huachacalla, Chuquicota, Turco, Curahuara y Totora ${ }^{1}$.

\section{Vialidad en el tramo Visviri- Parinacota}

Los restos de cultura material reconocidos en la prospección, tramo Visviri-Parinacota corresponden a tres tipos de evidencias. (a) Hallazgos Aislados (H.A): asociadas a artefactos o fragmentos de cerámica, madera, líticos, que se registran en forma acotada y discontinua. (b) Yacimientos Arqueológicos(Y.A): correspondenarestos de asentamientos funerarios, habitacionales, rupestres. (c) Rasgos Lineales (R.L); contextos referidos al tráfico caravanero de camélidos o mulares (senderos, caminos y huellas).

\section{Rasgo Cultural $\mathrm{N}^{\circ} 1$ Recintos en promontorio}

\section{Categoría: (Y.A) UTM 19k 466.288E 8033.080N}

Recintos de piedras construidos sobre faldeos de lomajes ribereños cercanos al Bofedal Río CaquenaCosapilla. Las uitectónicas son de forma circular, baja altura e hiladas en técnica simple con empleo de bloques rocosos de distintos tamaños, sin empleo de mortero (Figura 3). Su estado de conservación regular. El piso

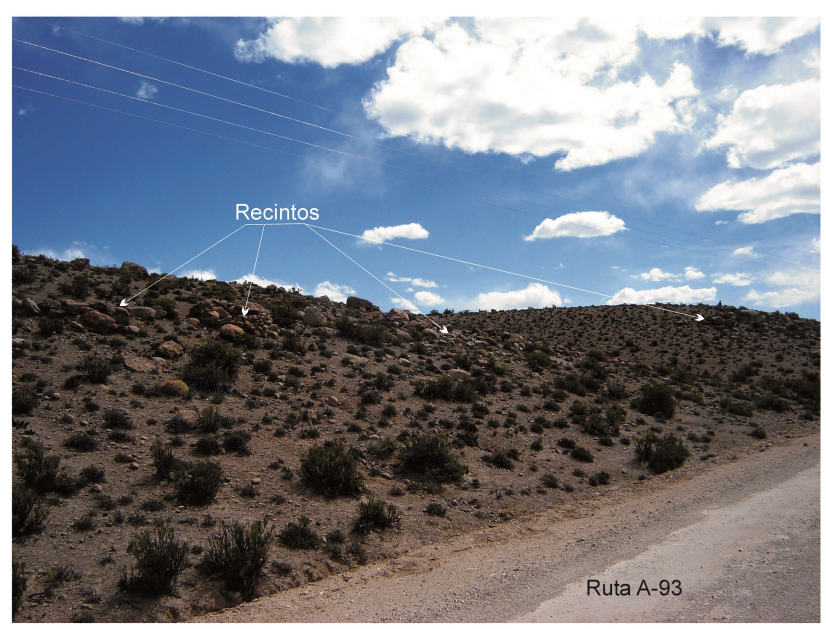

Figura 3. Rasgos 1a Recintos de piedra de forma circular.

Traits 1a Circular-shape stone enclosures. 
ocupacional interno resulta estrecho y no poseen indicadores constructivos secundarios que determinen accesos o divisiones internas. No se detectó presencia superficial de materialidad doméstica asociada a la construcción. Orientan su campo visual hacia la planicie de la ruta A-93 y el Bofedal del Río Caquena- Cosapilla.

\section{Rasgo Cultural $\mathbf{N}^{\circ} 2$ Residencias y Corrales}

\section{Categoría: (Y.A.) UTM 19k 466.656E 8032.090N}

Asentamiento de carácter residencial y para albergar animales. Se edificó aprovechando las cotas inferiores de un cerro de mediana altura, ubicado en las proximidades del caserío conocido como Pucara, en la ribera oeste de bofedal. Las estructuras están orientadas con dominio visual hacia el humedal, siguiendo el curso de la morfología esteoeste del cerro. La mampostería es rústica, responde a recolección selectiva de bloques rocosos desde los faldeos del cerro de abrigo, sin empleo de mortero y en hilada simple para determinar plantas con forma semirectangular y ovoide (Figura 4). La altura promedio de los muros es de 1,20 m, con espacios amplios de ocupación interna (Figura 5). El estado de conservación es regular. En las superficies internas y externas del suelo se hallaron fragmentos de cerámica de pasta de color naranja, y otros fragmentos que corresponden a cerámica torneada de confección tosca de 2 a $3 \mathrm{~cm}$ de espesor.

\section{Rasgo Cultural $\mathbf{N}^{\circ} 3$ Recinto amplio}

\section{Categoría: (Y.A.) UTM 19k 465.650E 8025.315N}

Estructura edificada en piedra, que presenta un espacio interior amplio; está demarcada por un muro perimetral, de piedras sin tratamientos de cantería y dispuestas en técnica de edificación mixta. Se ubica sobre lomajes que conforman una quebradilla seca aledaña a la ruta A-93. De acuerdo con la interpretación cartográfica, su referencia de ubicación es Pampa y Quebradilla de Chosguaya en las inmediaciones de la localidad deAncopujo. Cerca del vértice interior suroeste del recinto se halla un bloque lítico de $60 \mathrm{~cm}$ de alto y ejes de 2,10 x 1,70 cm, que posiblemente corresponda a un afloramiento natural que fue intervenido por el humano con la idea de tallar ocho cavidades cilíndricas, lo cual hace suponer que se trataría de una piedra tacita. Su conservación es mala, presenta un alto nivel de degradación con pérdida de material, meteorización ocasionada por condiciones ambientales y de origen antrópico. No se visualiza en superficie interna/externa del recinto otro tipo de materialidades culturales.

\section{Rasgo Cultural $N^{\circ} 4$ - $N^{\circ} 5$ - $N^{\circ} 6$ y $N^{\circ}$. Sendero \\ Categoría (R.L) UTM 19k 463.500E 8021.515N (norte) 19k 468.249E-8007.400N (sur)}

En las proximidades de la localidad de Chujlluta y al oeste de la calzada de la ruta A-93, junto a la red de electrificación, se registra evidencias de una ruta tropera (Figura 6). El entorno corresponde a lomajes sinuosos, de baja altura y que circundan el curso del lecho de una quebradilla seca que busca desembocar hacia el este en el sector de bofedales del Río Cosapilla. El trazado troperoque denota sus contornos entre pajonales y sobre una superficie terrosa color gris café, registra un ancho promedio de $50 \mathrm{~cm}$ y en su curso bordea las cotas inferiores de las elevaciones amortizando el uso de lechos de quebradillas y alejándose del borde oeste del gran bofedal. Hacia el norte conecta con

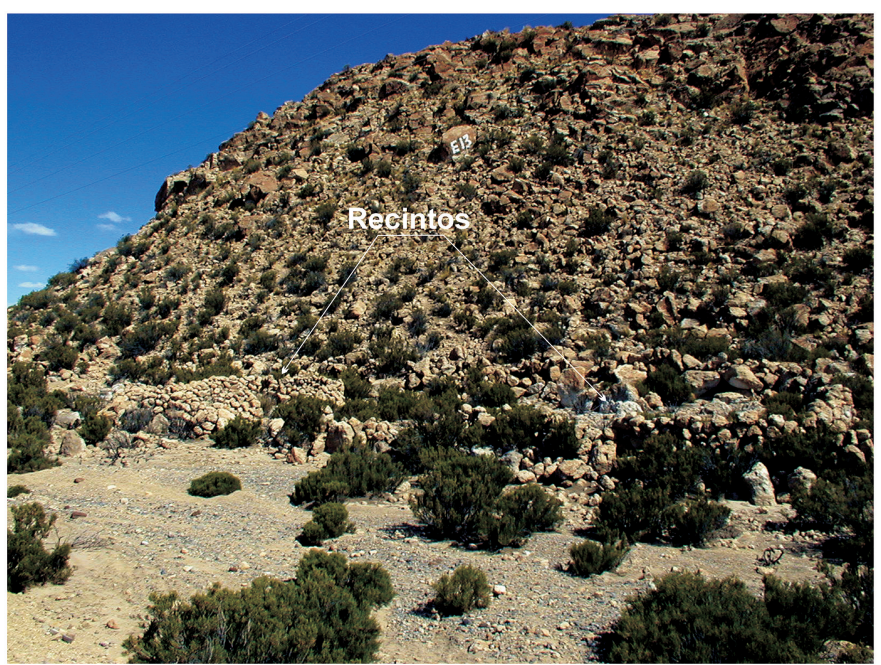

Figura 4. Rasgos 2a Recintos circulares de piedras, faldeos de cerro.

Traits 2 a Circular stone enclosures, hill slopes. 


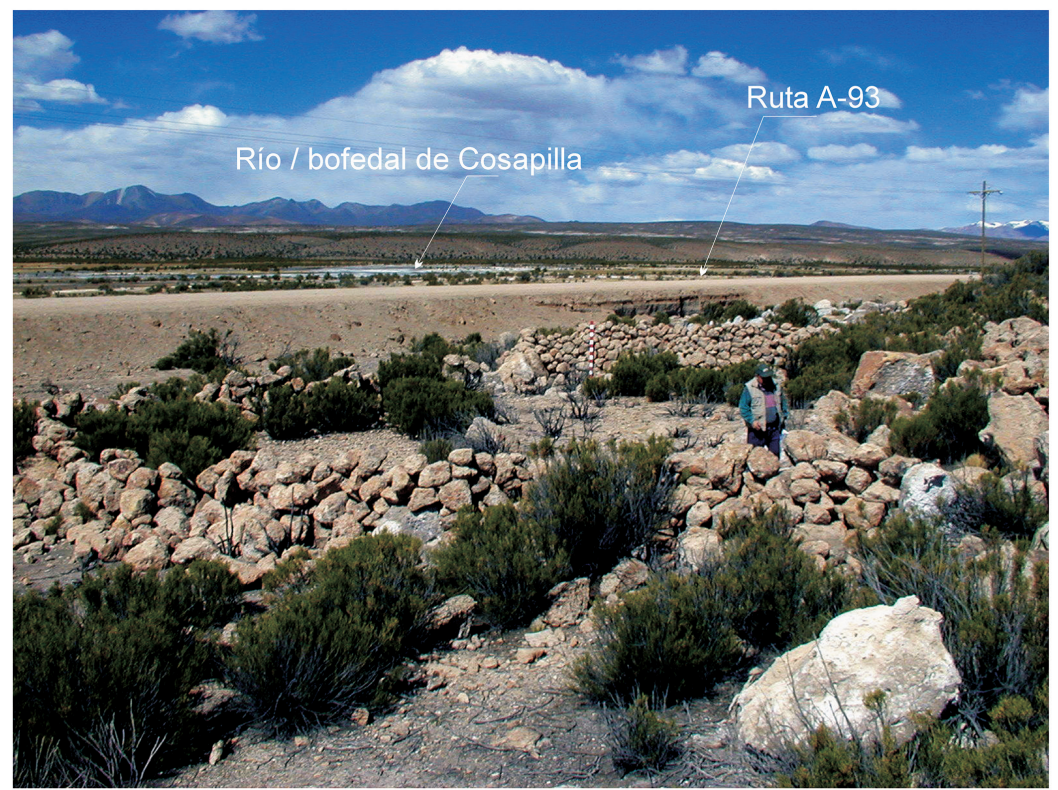

Figura 5. Rasgos 2c Recintos de piedra, al frente se ubica el Bofedal de Cosapilla y la ruta A-93.

Traits $2 c$ Stone enclosures, the Cosapilla wetlands and A-93 route are located on the opposite side.

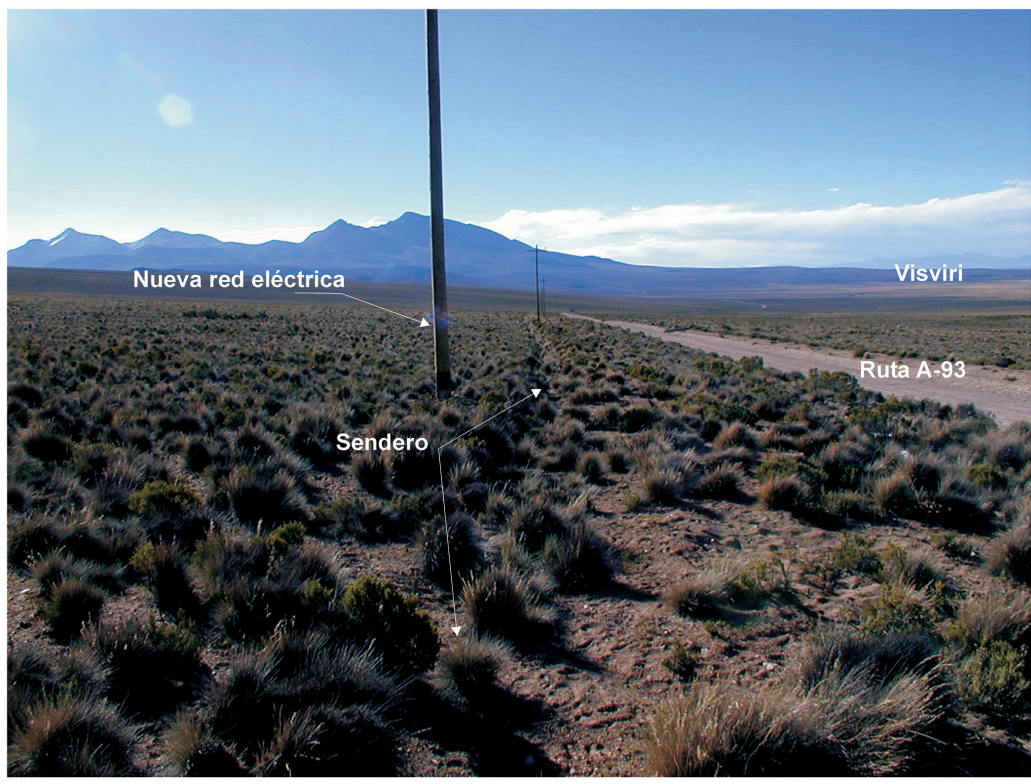

Figura 6. Rasgo 4-5-6 y 7. Trazado de Sendero, se ubica paralelo a la ruta A-23 y la red eléctrica Visviri-Parinacota. Trait 4-5-6 and 7. Path Trace, runs parallel to route A-23 and the Visviri-Parinacota grid. 
la localidad de Ancopujo distante $3 \mathrm{~km}$ y hacia el sur en una extensión de $19 \mathrm{~km}$ con el pueblo de Chañopalca.

\section{Rasgo Cultural $\mathrm{N}^{\circ} 8$ Capilla de Chañopalca}

\section{Categoría: (Y.A). UTM 19k 471.160E 8001.040N}

Pequeño complejo arquitectónico religioso del período virreynal-republicano; constituye el edificio de mayor relevancia en el caserío de Chañopalca. Está compuesto de tres unidades arquitectónicas orientadas hacia el noreste: capilla, calvario y torreón del campanario. En su construcción se empleó piedra canteada, proceso que permitió dar finas terminaciones en vértices de contramuros, vanos, dinteles y escaños. La alzada y afianzamiento de los bloques se logró con empleo de mortero y plomadas en ángulo agudo, lo cual otorga una mejor respuesta de resistencia a conductas en la mecánica del suelo y agentes naturales.

La sección de la capilla tiene una extensión de 9,55 m, ancho de 3,20 m y altura 3,20 m. El ábside es de planta semicircular, de material sólido, finiquitado con forma de arco. Presenta cubierta de techumbre en paja brava. El torreón del campanario en la actualidad se encuentra destruido en un 50\% a partir de la sección media a la sección superior. Antecedentes recopilados en el año 1989 mediante un Catastro Patrimonial de Arte Virreynal en los Andes, señalan que esta construcción poseía una altura de $3.90 \mathrm{~m}$. En su base, el polígono constructivo mide $1,65 \mathrm{~m}$ x 1,55 m. La base poligonal mide 90 × $90 \mathrm{~cm}$. Hay ausencia de simbología cristiana.

\section{Rasgo Cultural $\mathrm{N}^{\circ} 9, \mathrm{~N}^{\circ} 10, \mathrm{~N}^{\circ} 11, \mathrm{~N}^{\circ} 12, \mathrm{~N}^{\circ} 13$ - $\mathrm{N}^{\circ}$ 14 y $N^{\circ} 15$. Sendero}

\section{Categoría: (R.L.) UTM 19k 469.999E 7995.140N (norte) - 19k 470.590E 7989.400N (sur)}

Segmento de $6 \mathrm{~km}$ de longitud del trazado tropero. En esta área la ruta se desplaza sobre una serie de lomajes que provienen desde el oeste e incorporan al cerro Guaneguane. Por la pendiente norte tiene relación espacial con una apacheta en la cota de los $4.587 \mathrm{msm}$ y, al cruzar en dirección sur, comienza el descenso por la pampa arenosa-terrosa de Berenguela realizando un giro leve hacia el sureste a través de la quebrada y Bofedal de Leguíapalca y el Bofedal de Vulañuño, para conectarse finalmente con el Tambo de Parinacota. La conservación es regular por causal, naturales y antrópicas. Su identificación es posible por los cúmulos de paja brava que crecen en los costados, incluso marcando un desnivel del suelo.

\section{Rasgo Cultural $\mathrm{N}^{\circ} 16$ Corrales}

\section{Categoría: (Y.A.) UTM 19k 471.550E 7987.510N}

Conjunto de edificaciones destinadas a actividades de economía ganadera en directa relación con un complejo arquitectónico mayor de carácter residencial -administrativo identificado como Tambo. Se estableció el asentamiento sobre una amplia loma de superficie arenosa y cubierta de vegetación esteparia (Figura 7). En su base, por el flanco norte, limita con la Laguna de Guañacota

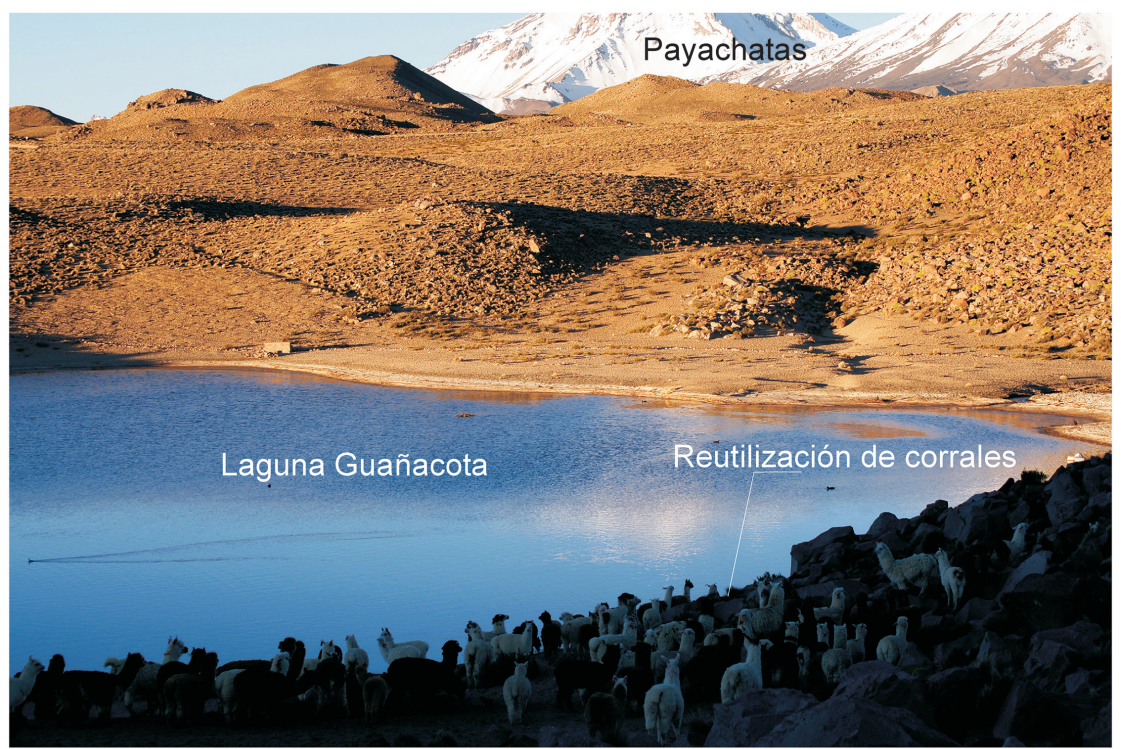

Figura 7. Rasgo 16. Estructuras de piedras usadas como corrales, se ubican frente a la Laguna de Guañacota. Trait 16. Stone structures used as pens located across from the Guañacota lagoon. 
mientras que por el sur lo hace con el Bofedal de Parinacota. Los recintos de corrales ocupan las cotas de un plano adyacentes a la ribera norte del bofedal, situación que resulta ideal para el control, resguardo y alimentación de la tropa de camélidos. La mampostería está definida por clastos dispuestos en doble hilada de piedras a partir de sólidos cimientos.

\section{Rasgo Cultural $N^{\circ} 17$ Poblado}

\section{Categoría: (Y.A.) UTM 19k 471.493E 7987.545N}

Complejo arquitectónico de carácter administrativo emplazado sobre una colina de superficie terrosa y material rocoso (Figura 8). Presenta una extensión en $230 \mathrm{~m}$ de este a oeste y $140 \mathrm{~m}$ de noreste a suroeste. Hacia el sector suroeste, el asentamiento se ubica sobre faldeos de cerros menores que se adentran en el Bofedal de Parinacota. Desde las cotas de cima se obtiene un amplio dominio visual de la planicie y de algunas montañas que enlazan con los distintos conos volcánicos que conforman la cadena de fuego altiplánica. El centro arquitectónico es incorporado a esta unidad topográfica a partir de nivelaciones de suelo aptas para establecer fundaciones de recintos habitacionales y corrales, sumando un total aproximado de 74 espacios delimitados para uso humano y animales domésticos. Algunos edificios testimonian actividad de cantería para depurar superficies de bloques, previo al ensamble de muros. El diseño arquitectónico del complejo se cimentó a partir de polígonos rectangulares y ovoides, observándose en algunos edificios mejor conservados soluciones de techumbre a dos aguas, accesos trapezoidales con escaños exteriores, espacios internos menores, y ventanas orientadas a los Payachatas (Figuras 9 y 10). En la detección de antecedentes tecnológicos, se constató en la superficie de todo el complejo arquitectónico la presencia de fragmentos de alfarería que presentan engobes rojo y decoración con diseños de color negro.

\section{Rasgo Cultural $\mathbf{N}^{\circ} 18$ Corrales y recintos habitaciones}

\section{Categoría: (Y.A) UTM 19k 471.798E 7987.442N}

Espacios domésticos y para albergar animales. Se ubican en el sector noreste del actual pueblo de Parinacota. La mampostería aplicada es mixta, simple y en doble hilada de piedras, a partir de basamentos en roca madre y bloques de cuerpos macizos. El pircado superior remata con rocas menores acuñadas sin empleo de mortero. los pisos internos poseen una gruesa capa de material orgánico fecal de camélidos.

\section{Rasgo Cultural $N^{\circ} 19$ Terraplén}

\section{Categoría: (Y.A.) UTM 19k 471.902E 7987.423N}

Plano artificial en cotas de cima de colina circundante, ubicada al oriente del pueblo de Parinacota.

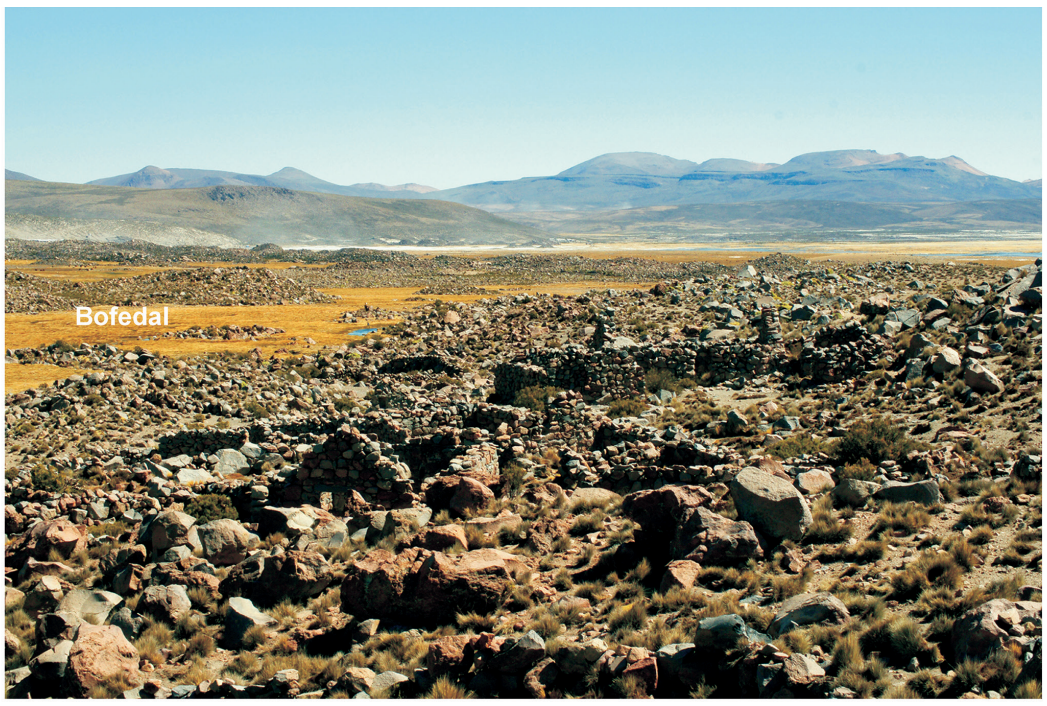

Figura 8. Rasgo 17a Estructuras de piedras componentes del sitio Poblado Viejo de Parinacota, asentamiento ubicado frente del Bofedal de Parinacota.

Trait 17a. Stone structures from the Poblado Viejo de Parinacota site, settlement located across from the Parinacota wetlands. 


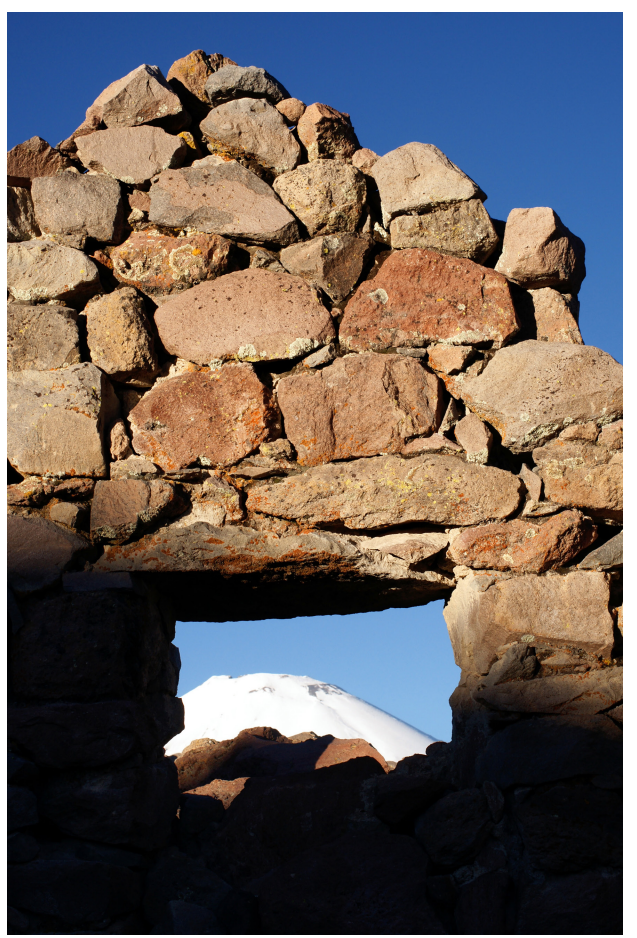

Figura 9. Vista de los Nevados de Payachatas a través de una ventana trapezoidal en el sitio Poblado Viejo de Parinacota.

View of the Nevados de Payachatas through a trapezoidal window in the Poblado Viejo de Parinacota site.

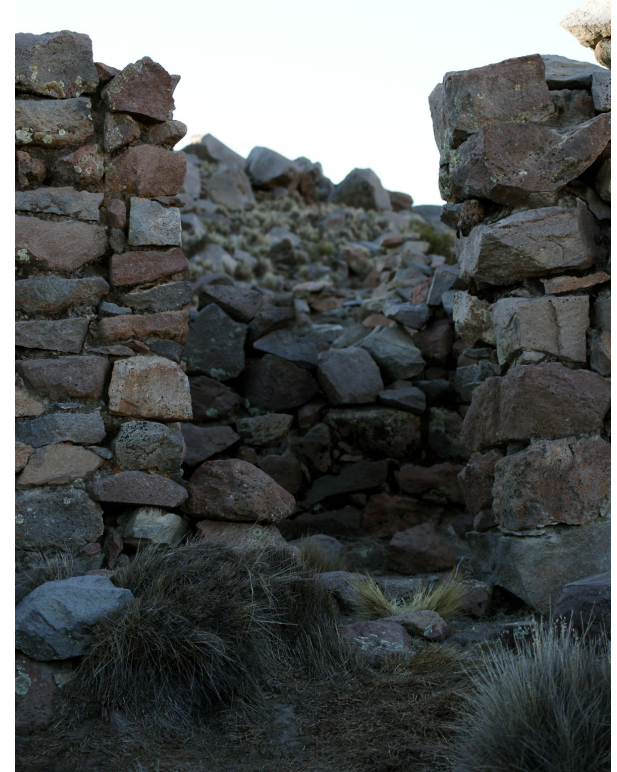

Figura 10. Espacio de ingreso al recinto 69, presenta jambas en mampostería mixta, sector 4 , sitio Pueblo Viejo de Parinacota.

Entrance space to enclosure 69, mixed masonry jambs can be observed, Sector 4, Pueblo Viejo de Parinacota site.
El área presenta varias estructuras distribuidas en distintos niveles a partir de senderos de peregrinaje y servicio hacia calvarios cristianos, estación meteorológica, corrales y terraplén posiblemente construido para ceremonias rituales etnográficas. Llaretales y pajonales matizan de verde los tonos áridos de los faldeos. El espacio de $23 \mathrm{~m}$ por $17 \mathrm{~m}$, orienta su muro de contención hacia el sector oriente donde se ubican los bofedales y las cumbres de los nevados de Parinacota y Pomerape. El detalle arquitectónico está definido por un pircado a nivel de suelo muy simple, en el que se emplearon rocas pequeñas y grandes para contener el material terroso grisáceo que compone la superficie de la colina. Se constató fragmentación alfarera de superficies de color naranja y café grisáceo.

En síntesis, la prospección arqueológica desarrollada en el tramo Visviri-Parinacota arrojó 19 rasgos culturales (Tabla 1). Categorizando dichos rasgos estos corresponden a: (a) Senderos, los que se caracterizan por restos de huellas dejadas por el paso de caravanas de animales domésticos (llamas). (b) Corrales, recintos para albergar animales, vinculado a una economía de pastores de origen prehispánica, histórica y etnográfica. Estos recintos se construyeron en lugares de abrigo rocoso, presentan planta arquitectónica de forma circular, mampostería gruesa, sin trabajo de cantería. En algunos sectores hay reutilización de estos recintos tanto para albergar animales como personas. (c) Recintos con funciones domésticas, presentan formas circulares, de 5 a $7 \mathrm{~m}$ de diámetro, los muros están construidos a una o doble hiladas de piedras, en su interior se hallaron fragmentación de cerámica de engobes rojo, naranja, de superficies de color gris y café. (d) Recintos pequeños de forma circular, de los cuales no hemos podido definir su función.

\section{Rasgo Cultural 17 (Y.A.). El asentamiento Pueblo Viejo de Parinacota como eje articulador del transecto Visviri- Parinacota}

Dentro del eje que articula el transecto VisviriParinacota, por su volumen, sistema constructivo, arquitectura, variedad de recintos resalta el yacimiento arqueológico Pueblo Viejo de Parinacota (R. 17) que se trataría de un asentamiento de carácter domésticoceremonial, construido durante el periodo Tardío (PT) de la prehistoria regional (Muñoz et al. 2011-2016). El sitio descrito mediante levantamiento topográfico e imágenes fotográficas y satelitales permite inferir cuatro sectores orientados de este a oeste (Muñoz et al. 2011-2016). El primer sector, ubicado en el margen este, corresponde a una concentración de catorce recintos cuya planta arquitectónica predominante es de ocho recintos de forma rectangular, dos recintos de forma circular y cuatro de forma ovoide ${ }^{2}$. Sus paredes fueron construidas a doble hiladas de piedras, las que se alzaron sobre un terraplén primario a modo de loza que emerge sobre la superficie del 
Tabla 1. Rasgos identificados en la ruta Visviri-Parinacota.

Traits identified in the Visviri-Parinacota route.

\begin{tabular}{|c|c|c|c|c|c|c|c|}
\hline \multirow{2}{*}{$\begin{array}{l}\text { № Rasgo } \\
\text { Cultural }\end{array}$} & \multicolumn{2}{|c|}{ Coordenadas Utm Datum: Wgs 84} & \multirow{2}{*}{ Adscripción Temporal } & \multirow{2}{*}{ Descripción General } & \multirow{2}{*}{ H.A. } & \multirow{2}{*}{ Y.A. } & \multirow{2}{*}{ R.L. } \\
\hline & Este & Norte & & & & & \\
\hline 1 & 466.125 & 8033.080 & Prehisp./etnográfico & Recintos aislados en promontorio & & $\mathrm{X}$ & \\
\hline 2 & 466.680 & 8032.090 & Prehispano & $\begin{array}{l}\text { Recintos económicos (corrales) y } \\
\text { residencias (área cercana a pucara) }\end{array}$ & & $\mathrm{X}$ & \\
\hline 3 & 465.650 & 8025.315 & Etnográfico prehispano & Gran corral (área Ancopujo) & & $\mathrm{X}$ & \\
\hline 4 & 463.500 & 8021.515 & Prehispano & Área Chujlluta. Sendero. Vértice norte & & & $\mathrm{X}$ \\
\hline 5 & 463.360 & 8021.340 & Prehispano & Área Chujlluta. Sendero. Vértice sur & & & $\mathrm{X}$ \\
\hline 6 & 468.100 & 8007.500 & Prehispano & Sendero, tramo. Vértice norte & & & $\mathrm{X}$ \\
\hline 7 & 468.249 & 8007.400 & Prehispano & Sendero, tramo. Vértice sur & & & $\mathrm{X}$ \\
\hline 8 & 471.160 & 8001.040 & Colonial/Etnográfico & $\begin{array}{l}\text { Capilla Virreinal, Chañopalca } 32 \mathrm{~m} \text { de } \\
\text { ruta A-123 }\end{array}$ & & $\mathrm{X}$ & \\
\hline 9 & 469.999 & 7995.140 & Prehispano & Sendero, tramo alterado. Vértice norte & & & $\mathrm{X}$ \\
\hline 10 & 468.945 & 7994.565 & Prehispano & Sendero, tramo alterado. Vértice sur & & & $\mathrm{X}$ \\
\hline 11 & 468.860 & 7992.875 & Prehispano & Sendero, final vértice norte & & & $\mathrm{X}$ \\
\hline 12 & 468.574 & 7992.440 & Prehispano & Sendero, intermedio & & & $\mathrm{X}$ \\
\hline 13 & 469.380 & 7991.250 & Prehispano & Sendero, vértice sur. Al este ruta A-123 & & & $\mathrm{X}$ \\
\hline 14 & 470.590 & 7989.400 & Prehispano & Sendero al N. Choipacollo, vértice sur & & & $\mathrm{X}$ \\
\hline 15 & 470.860 & 7989.270 & Prehispano & Sendero al N. de Choipacollo. Vértice sur & & & $\mathrm{X}$ \\
\hline 16 & 471.550 & 7987.510 & Prehispano & Corrales asociados a tambo & & $\mathrm{X}$ & \\
\hline 17 & 471.685 & 7987.545 & Prehispano & Poblado Tambo & & $\mathrm{X}$ & \\
\hline 18 & 471.880 & 7987.470 & $\begin{array}{l}\text { Prehispano } \\
\text { etnográfico }\end{array}$ & Corrales & & $\mathrm{X}$ & \\
\hline 19 & 471.875 & 7987.450 & Prehispano etnográfico & Terraplén ritual & & $\mathrm{X}$ & \\
\hline
\end{tabular}

H.A.: Hallazgo Arqueológico, Y.A.: Yacimiento Arqueológico, R.L.: Rasgo Lineal.

terreno. Algunas piedras presentan trabajo en cantería en su superficie externa, para ser utilizadas en las soluciones de esquinas. Su estado de conservación es deficiente, con escasos muros que conservan sus alturas originales. Los R.6 y R.7 S que presentan mejor estado de conservación han permitido inferir el modelo arquitectónico.

La distribución de estos catorce recintos fue probablemente concebida en torno a espacios amplios, constituyéndose en espacios de convergencia y desplazamiento. El R.12 por sus dimensiones y mampostería correspondería a un corral. En este recinto observamos evidencias de reutilización y modificación de la arquitectura mediante el desplazamiento de bloques.

El recinto 4, donde fue tomada la muestra de cerámica fechada en 1440 DC, ocupa el área central del poblado muy próximo a las cotas de cima, es de planta rectangular observándose casi a nivel de cimiento, su piso de ocupación interna es compacto, probablemente tuvo un acceso por la pared noreste. Los recintos R.6, R.7, R.8, R.9, R.10 y R.76 flanquean por el sector oeste y noroeste al R.4, generando un espacio amplio y libre de construcción. Por el flanco noreste externo del R.4. distante unos $4 \mathrm{~m}$, se detectó la presencia de un muro que se orienta de este a oeste y norte a sur, que probablemente fue parte del muro perimetral.

El valor que adquiere el transecto vial VisviriParinacota, especialmente en lo que fue su trazado final donde se inserta el sector de Parinacota, se fundamenta en que allí se construyó el poblado Pueblo
Viejo de Parinacota, centro poblacional sobre el cual se generó una red de senderos que involucró una serie de asentamientos y territorios productivos de la puna. Entre las redes viales que vinculan este poblado con otros asentamientos, tenemos evidencias en la parte alta de este asentamiento de antiguos trazos de senderos, los que estarían comunicado este poblado, por el este, con el Lago Chungará, donde en sus inmediaciones se halla el tambo del mismo nombre. La distancia entre este tambo y Pueblo Viejo de Parinacota es de $26 \mathrm{~km}$. Hacia el oeste las redes se desplazan por serranías, planos y bofedales comunicándose con el sector de Tacora, distante $53 \mathrm{~km}$ de Parinacota, donde se hallan los tambos de Ancara y Tacora. Por el noreste a las redes viales se desplazan hacia el Tambo de Pisarata, ubicado a $26 \mathrm{~km}$ de Parinacota, en el sector de Caquena, cercano al bofedal del Río Cosapilla.

De lo anterior, se desprende que en el sector de Parinacota hubo una interacción directa con todos los espacios productivos que ofreció la puna, lo cual evidentemente habría permitido que las comunidades de Pueblo Viejo de Parinacota controlaran la producción y generaran un mayor intercambio económico con las poblaciones de la puna.

\section{Discusión sobre los Restos Materiales Hallados en el Asentamiento Pueblo Viejo de Parinacota}

Del estudio desarrollado por Muñozetal. (2011-2016) se desprenden una serie de comentarios relacionados con 
el sistema constructivo del asentamiento, las evidencias de alfarería halladas y las fechas obtenidas a través del método de Termoluminiscencia. Esta información es fundamental, ya que nos permite conocer la importancia de este emplazamiento ubicado en la puna del extremo norte de Chile y sus conexiones con otros asentamientos contemporáneos emplazados al otro lado de la frontera, en el altiplano Boliviano, y además, sobre la ocupación del sitio en la época colonial y republicana.

1. Desde el punto de vista arquitectónico se constituye como el mayor poblado construido en la puna del extremo norte de Chile, se halla conformado por recintos habitacionales y la edificación de un tambo (sector 4, R. 55).

2. El poblado presenta cuatro áreas sectorizadas, orientadas de este a oeste, con una clara orientación hacia el sur, donde se obtiene el dominio visual del gran Bofedal de Parinacota y de los nevados de los Payachatas (Figura 11).

3. Los flancos este y oeste corresponden a las áreas habitacionales, mientras que hacia el centro del poblado las áreas fueron destinadas a corrales, constituyéndose como las áreas económicas de estas poblaciones de pastores.

4. Los recintos rectangulares más pequeños al parecer cumplieron funciones de almacenamientos (p.ej., R.44, R.53, R.54, R.72). Sugerimos esta hipótesis por tratarse de pequeños espacios de 2 a $3 \mathrm{~m}$ respecto a los ejes mayores, ubicándose en un ordenamiento lineal con respecto a edificios de mayor envergadura, como p.ej., R.52 y R. 53 alineados con respecto al R.51.

5. Recintos para la función de tambo lo observamos en el sector 4. Corresponden a cuatro estructuras de forma rectangular, vinculadas con el sendero (R.47), el que está delimitado por piedras a modo de solera.

6. Las áreas centrales, como corrales, por estar en las cotas bajas permiten un flujo expedito de animales de arreo, vinculados con el sector bofedal y lagunas.

7. El análisis de los estilos decorativos, manufactura, tratamiento de la superficie y estándar de pasta en la cerámica nos señala que una vez el poblado Pueblo Viejo de Parinacota, fue ocupado por las poblaciones Carangas del periodo Intermedio Tardío (PIT) y posteriormente por poblaciones Caranga influenciada por los Inca, periodo Tardío (PT); la presencia de fragmentos de cerámica torneada con esmalte, indicaría que el asentamiento también fue ocupado durante la Colonia incluso hasta el siglo XX, aseveración que se fundamenta en el contexto de la reocupación del recinto 45 , sector 4 , donde se observa la colocación de una puerta de madera en la pared noreste (Figura 12).

8. Los fragmentos de cerámicas revisados presentan diferencias en su pasta, pero existe un denominador

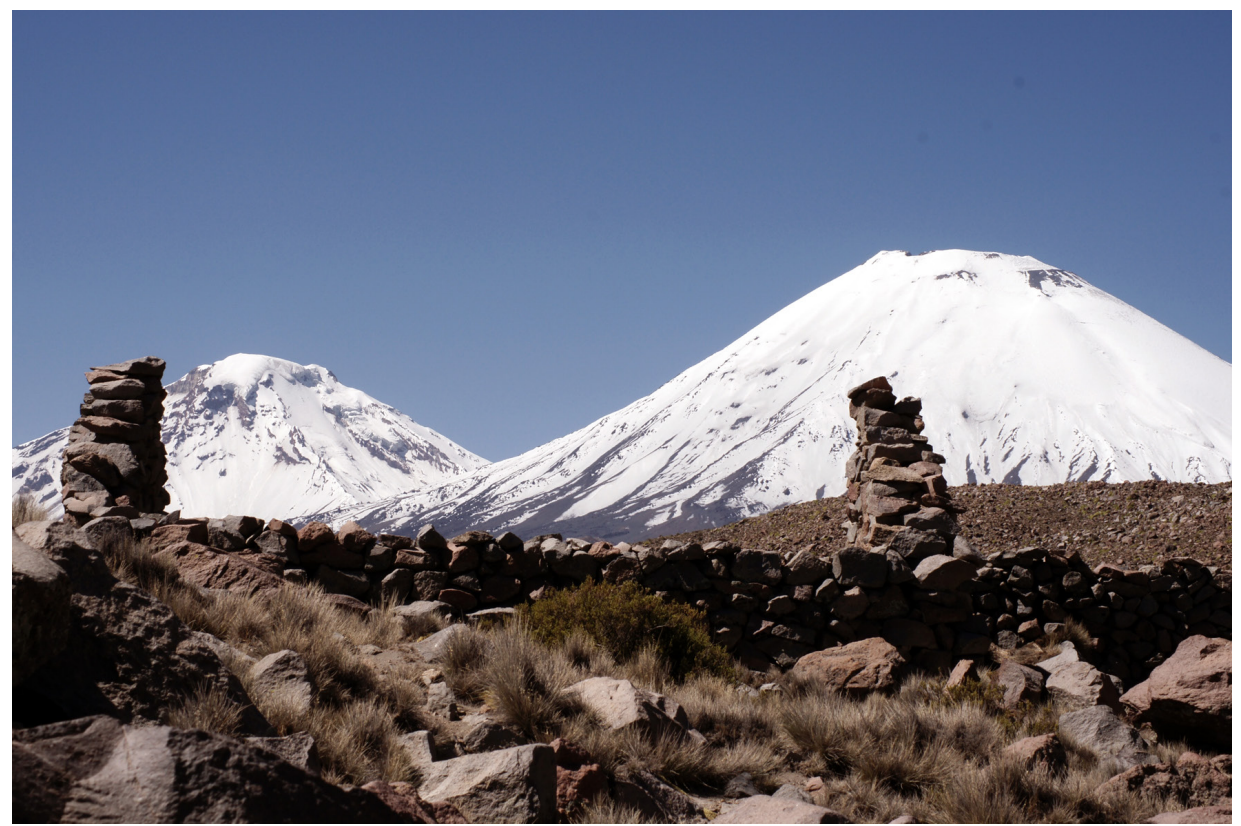

Figura 11. Estructura rectangular, recinto 55, construida en piedra; sitio Poblado Viejo de Parinacota. Al fondo, los nevados Payachatas.

Rectangular stone structure, enclosure 55; Poblado Viejo de Parinacota site. In the background, Nevados de Payachatas. 
común en un porcentaje importante de ellas, como es la presencia de Mica o Moscovita, que es un componente característico de las arcillas de la sierra y altiplano. Se infiere el uso y la manufactura de arcillas locales principalmente en la realización de los tiestos cerámicos.

9. Los estándares de pasta más frecuente son el 400 y 300, que están vinculadas a las pastas que se han clasificado para el periodo Intermedio Tardío o Desarrollo Regional, en los valles y la costa de Arica. La diferencia más importante es que las del valle y costa son menos compactas, pero existe una similitud importante en su preparación y tratamiento de manufactura y quema.

10. La reconstrucción de formas que se presentan, corresponden a morfologías prehispánicas como ollas y pucos, piezas que fueron utilizadas para uso doméstico.

11. La revisión de esta cerámica reafirma la tesis que existe respecto de una diferenciación de manufacturas para objetos de uso ritual y ceremonial con relación a objetos de uso doméstico, siendo éstas últimas con acabados menos delicados, sin decoración pintada y con quemas más descuidadas.

12. La calidad de cocción completa e incompleta que presentan los tiestos reafirma la hipótesis de que

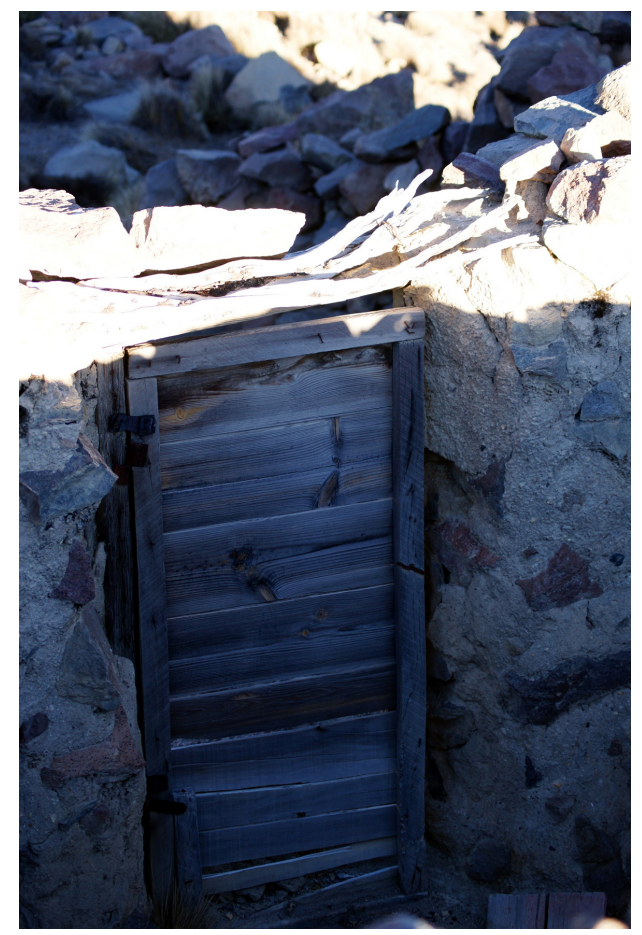

Figura 12. Reocupación de una estructura prehispánica de piedra, sitio Poblado Viejo de Parinacota, R. 45, pared noreste, por medio de la construcción de una puerta de material ligero.

Rectangular stone structure, enclosure 55; Poblado Viejo de Parinacota site. In the background, Nevados de Payachatas. la cerámica de uso utilitario no tiene el mismo cuidado en el proceso de manufactura, con relación a la cerámica de uso ritual. En el estudio se aprecia que la quema no tiene una dedicación especial al aplicar fuego. El tratamiento pulido de acabado que se ha dado en general a la cerámica manifiesta una importante presencia en esta revisión. El mayor porcentaje de cerámica sin decoración revisada se presenta en objetos que fueron confeccionados con un fin de uso en actividades domésticas.

13. La forma de fracturarse de la cerámica, donde interviene el calor y temperatura a la que han sido sometido los tiestos y la calidad de las arcillas, permite apreciar la existencia de una cocción deficiente y tal vez descuidada, que sigue reafirmando la condición a la que fueron destinados los tiestos. A su vez, demuestra la existencia de un pequeño porcentaje de objetos de mejor calidad que, al parecer, son foráneos con pastas del altiplano, pero de uso y tecnología de buena calidad. Por las características técnicas en la cerámica se puede observar una importante ocupación del sitio en la época prehispánica, con presencia menos relevante durante el periodo de contacto hispano indígena.

\section{Comentarios sobre la cronología, alfarería, arquitectura y ritualidad del paisaje en el poblado Pueblo Viejo de Parinacota}

\section{Cronología y cerámicas}

Las fechas obtenidas para la cerámica halladas en el poblado Pueblo Viejo de Parinacota -1440 DC y 1510 DC- indican que dicho asentamiento fue ocupado durante la influencia del Tiwantinsuyo; sin embargo, la cerámica fechada se vincula al Horizonte Negro sobre Rojo, estilo característico de los pastores vinculados a las poblaciones Carangas y Pacajes-Inca (Tabla 2, Figuras 13 y 14). Este estilo se caracteriza por pastas rojas y tratamientos superficiales acabados, tanto pulidos como bruñidos, presentan diseños decorativos con formas zoomorfas y motivos geométricos remarcando las figuras circulares (Michel 1996, 2000). Según Muñoz y Chacama (2006) esta cerámica se halla distribuida en todos los asentamientos donde hay registros de edificaciones de tambos en la puna del extremo norte de Chile.

Los fechados obtenidos por Muñoz y Chacama (2006), aplicando el método de Termoluminiscencia, arrojaron las siguientes dataciones para el estilo Negro sobre Rojo: (a) Tambo de Pisarata, 1535 DC (UCTL/982), fragmento de forma de puco; (b) Tambo de Ancara, 1590 DC (UCTL/984), fragmento de 
Tabla 2. Fechados obtenidos por el método de la Termoluminiscencia, sitio Pueblo Viejo de Parinacota.

Dates obtained by Thermoluminescence method, Pueblo Viejo de Parinacota site.

\begin{tabular}{|c|c|c|c|c|c|c|c|c|}
\hline MUESTRA & $\mathrm{N}^{\circ}$ & REGISTRO & P (Gy) & D (Gy/año) & $\begin{array}{l}\text { EDAD (años } \\
\mathrm{AP})\end{array}$ & DESCRIPCIÓN & FOTO & FECHA \\
\hline UCTL 2348 & 1 & $\begin{array}{l}\text { Recinto 4, } \\
\text { superficial, } \\
\text { pueblo viejo } \\
\text { de Parinacota }\end{array}$ & $1,60 \pm 0,13$ & $2,80 \times 10^{-3}$ & $570 \pm 50$ & $\begin{array}{l}\text { Puco, bruñido } \\
\text { Estilo negro } \\
\text { sobre rojo, pasta } \\
\text { fina estándar } \\
220\end{array}$ & & $1440 \mathrm{DC}$ \\
\hline
\end{tabular}

\begin{tabular}{|c|c|c|c|c|c|c|}
\hline UCTL 2349 & 2 & $\begin{array}{l}\text { Recinto 46, } \\
\text { superficial, } \\
\text { pueblo viejo } \\
\text { de Parinacota }\end{array}$ & $1,50 \pm 0,12$ & $3,00 \times 10^{-3}$ & $500 \pm 50$ & $\begin{array}{l}\text { Puco, bruñido. } \\
\text { Estilo negro } \\
\text { sobre rojo, } \\
\text { pasta muy fina } \\
\text { estándar } 210\end{array}$ \\
\hline
\end{tabular}

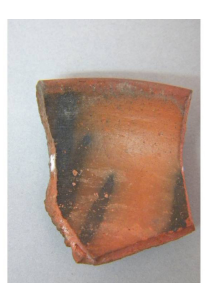

$1510 \mathrm{DC}$

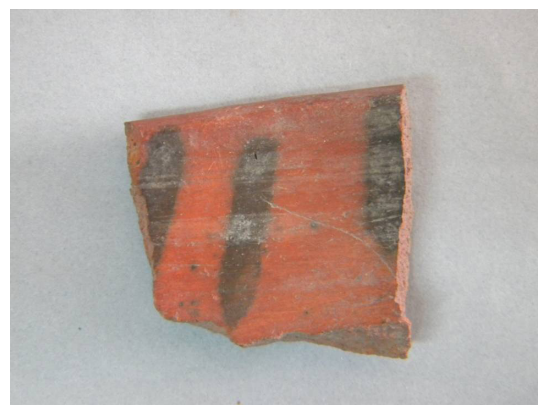

Figura 13. Registro UCTL 2349. Fragmento de cerámica de pasta fina, bruñida. Estilo Negro sobre Rojo. Fechado 1440 DC.

UCTL record 2349. Fragment of fine paste, burnished ceramic. Black style on red. Dated 1440 AD.

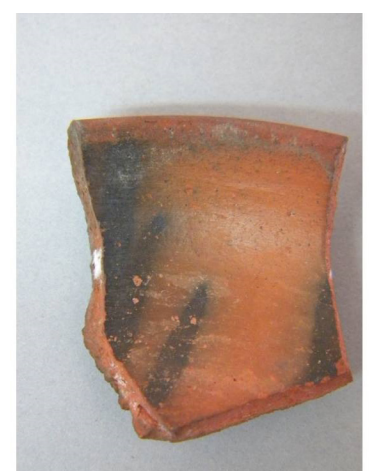

Figura 14. Registro UCTL 2348. Fragmento de cerámica de pasta fina, bruñida. Estilo Negro sobre Rojo. Fechado 1510 DC.

UCTL record 2348. Fragment of fine paste, burnished ceramic. Black style on red. Dated 1510 AD. forma de aríbalo; y (c) Tambo de Chungará, 1695 DC (UCTL/983), fragmento de forma de olla.

La cerámica estudiada de Pueblo Viejo de Parinacota correspondería a una cerámica local vinculada al periodo Prehispánico Tardío (Figura 15), y un porcentaje menor a la cerámica HispanoIndígena. A manera de interpretación, podemos señalar que el poblado habría sido fundado por etnias locales prehispánicas vinculadas a poblaciones Carangas (Michel 1996 y 2000). Para la confección de los alfares se utilizaron pastas locales, las que tienen un fuerte componente de mica; la cocción es deficiente y descuidada, y por lo tanto las pastas son menos compactas. Las formas corresponden a ollas y

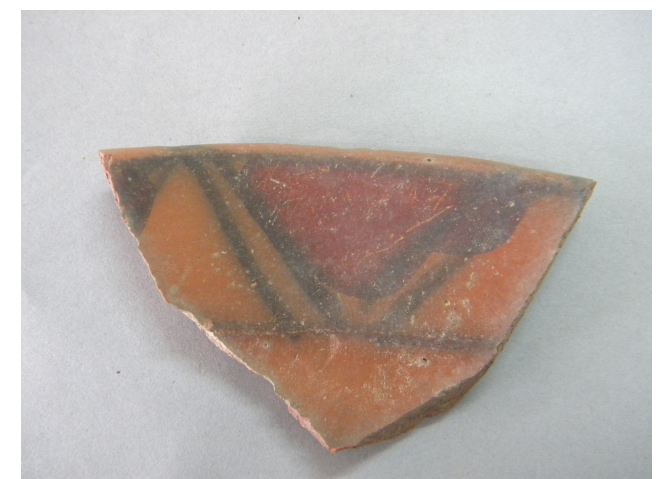

Figura 15. Fragmento de cerámica estilo negro sobre rojo. Decoración lineal.

Black on red style ceramic fragment. Linear decoration. 
pucos usadas con fines domésticos (preparación de alimentos, etc.); sin embargo, junto a estos ceramios aparece también un grupo menor de tiestos con mejor calidad de confección, probablemente utilizados en ceremonias, que por sus pastas se hallan vinculados a la tradición alfarera altiplánica asociada con las

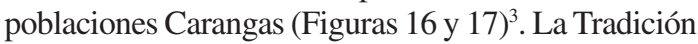
de cerámica Negro sobre Rojo se encuentra presente en todo el Altiplano de Bolivia con diferencias regionales marcadas, como lo señalan Catacora et al (2002), Condarco et al (2002), Michel (2008), Cruz (2007), Lecoq (1997), Lima y González (2014), Rivera (2014), Van Buren y Weaver (2014), Villanueva (2015), Torrez (2019). Para Muñoz (1996) y Michel (2000), un rasgo representativo del estilo Caranga hallado en los valles del extremo norte de Chile correspondería al estilo Chilpe, definido por Dauelsberg (1972/1973) para el valle de Azapa.

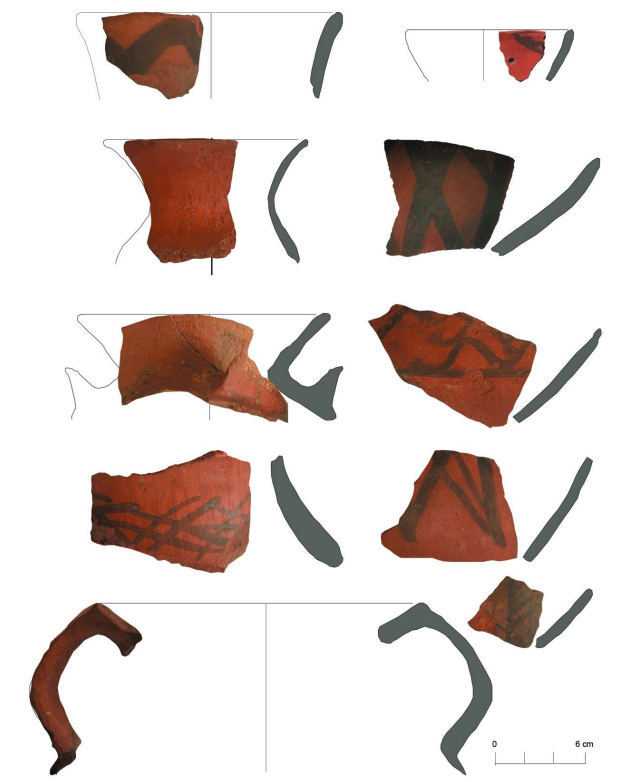

Figura 16. Bordes y asas, cerámica Carangas. Sitio Inca Marka (tomado de Torrez 2019:130). Edges and handles, Carangas ceramic. Inca Marka site (taken from Torrez 2019:130).

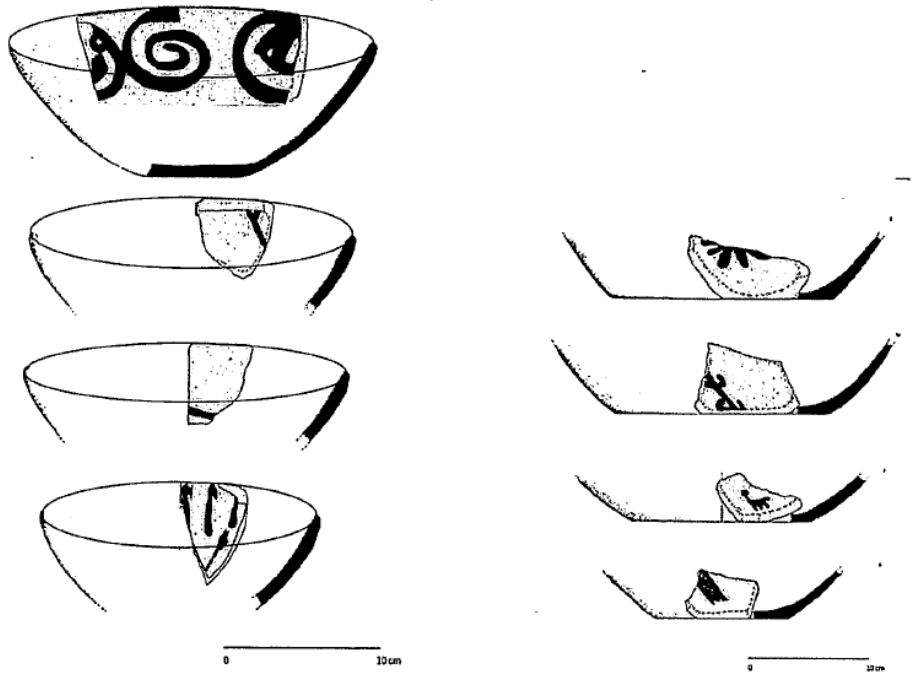

Figura 17. Dibujo de cuencos y bases, cerámic a Carangas (Michel 1996, tomado de Torrez Torrez 2019:51). Drawing of bowls and bases, Carangas ceramic (Michel 1996, taken from Torrez 2019:51). 
Los estilos Altiplánicos o de Engobes Rojos son un conjunto de cerámicas de pastas rojas y tratamientos superficiales acabados (pulidos y bruñidos), que es en sí la diferencia más notoria con el grupo anterior. En términos generales, la distribución cronológica de este estilo es más tardía que la Tradición Negro sobre Rojo, por lo que su relación cultural está directamente ligada a la presencia Inca en la zona.

\section{Poblado}

$\mathrm{La}$ arquitectura que presenta el asentamiento Pueblo Viejo de Parinacota nos recuerda, por un lado, el estilo constructivo propio de los asentamientos vinculados con las poblaciones locales preincas ubicados en la puna del altiplano sur andino. Esta se caracteriza por la presencia de recintos de forma circular, vinculados al núcleo doméstico residencial de la población y recintos de forma rectangular, asociados a la estructura administrativa del poblado relacionado al patrón arquitectónico Inca. Algunas de estas construcciones corresponden a depósitos, Qollcas, plataformas ceremoniales, Ushnus, y un edificio que pudo haber cumplido la función de Kallanca. La presencia de estas estructuras refleja una sociedad, la Inca, que tuvo como objetivo más que explotar el medio circundante, administrar a la población local en relación con sus recursos económicos, específicamente la ganadería de camélidos. Su arquitectura refleja espacios para la administración y espacios para la ritualidad, por lo tanto, gobierno y religión, dos piezas claves en la expansión del Incanato que se reflejan claramente en la arquitectura del asentamiento Pueblo Viejo de Parinacota.

Desde el punto de vista de su planificación, en Pueblo Viejo de Parinacota existe una clara orientación a construir los recintos mirando hacia el este donde se ubican los nevados, lo que incluye los recintos domésticos, administrativos y ceremoniales (Figura 18). Esta planificación difiere de los poblados construidos en la sierra y precordillera ubicados a $3.000 \mathrm{msm}$ aproximadamente, donde los sitios administrativos como los tambos y ceremoniales como kallankas y ushnus se construyeron separadamente de la aldea local ${ }^{4}$. Respecto a la red de senderos detectada en Pueblo Viejo de Parinacota, estos se caracterizan por huellas dejadas por el paso de animales domésticos y pastores. Esta red sugiere que el área donde se asentó dicho poblado fue un espacio de movilidad e intercambio vinculado con pastores altoandinos. Esta movilidad habría integrado poblados como Turko, Sabaya, Huachacalla, entre otros, dentro del circuito del señorío Caranga, y otros a mayor distancia como Caquiaviri, Callapa, Caquingora vinculados al señorío Pacaje (Figura 19).
Hacia el sector noreste vemos una red de senderos que se dirigen hacia el sector de Tacora, donde se ubica el Tambo de Ankara y cuyas redes alcanzan la zona de Tarata al sur de Perú (Figura 20). Estas redes, al igual como ocurre con el extremo norte de Chile, alcanzan poblados de pastores de puna y aldeas de agricultores que se ubican en la precordillera. A nivel local, otras redes se dirigen al Bofedal de Caquena y Chungará, donde se ubican los tambos de Pisarata y Chungara (Figura 21 y 22), lo cual conforma un entramado en el altiplano chileno, cuyos puntos de convergencia se hallan en la puna peruana-boliviana.

Hacia el oeste los senderos se desplazan hacia menores niveles de altura, como la precordillera o sierra de Arica (3.000 a $2.500 \mathrm{msm}$ ), donde se hayan asentamientos y recursos hídricos permanentes. $\mathrm{La}$ movilidad generada a través de estos senderos involucró rutas que conectan a las poblaciones de la puna con los valles costeros, siendo puntos de interacción y convergencia el sector de Zapahuira, Chapiquiña, Belén, Saxamar y Cobija, donde se concentran los mayores poblados estudiados por Dauelsberg (1983), Muñoz et al. (1987), Romero (2005), Muñoz y Chacama (2006), Saintenoy et al. (2017), Santoro et al. (2004), Schiappacasse y Niemeyer (1999), vinculados con las poblaciones locales del periodo Intermedio Tardío y Tardío.

ElpobladoPuebloViejodeParinacotaposiblemente fue parte de la organización sociopolítica y territorial del señorío Caranga, sistema que se explica a través del modelo de verticalidad escalonada estructurada sobre la base de un sistema de asentamientos jerarquizados (Durston e Hidalgo 1997). En el caso de Pueblo Viejo de Parinacota, este habría estado conectado con los centros primarios situados en la localidad de Turco, parcialidad de Hatun Caranga. En cuanto a su vinculación con los centros secundarios, por su ubicación estratégica es probable que desde este asentamiento hayan salidos rutas que conectaron con Socoroma y Belén (Tocoroma), poblados que habrían sido centros productores, redistributivos y de control estratégico. En dichos pueblos habrían residido los caciques, los cuales habrían mantenido relaciones directas con los mallkus altiplánicos.

\section{Ritualidad Paisajística}

Desde el punto de vista de su planificación y construcción, en el poblado Pueblo Viejo de Parinacota observamos una estrecha relación con el entorno, en concreto con los nevados de los Payachatas y el Bofedal de Parinacota. Si consideramos los planteamientos de Rivière (1982), en el sentido que cada pueblo tiene una montaña como elemento protector e identitario vinculado con los orígenes, representando la deidad 


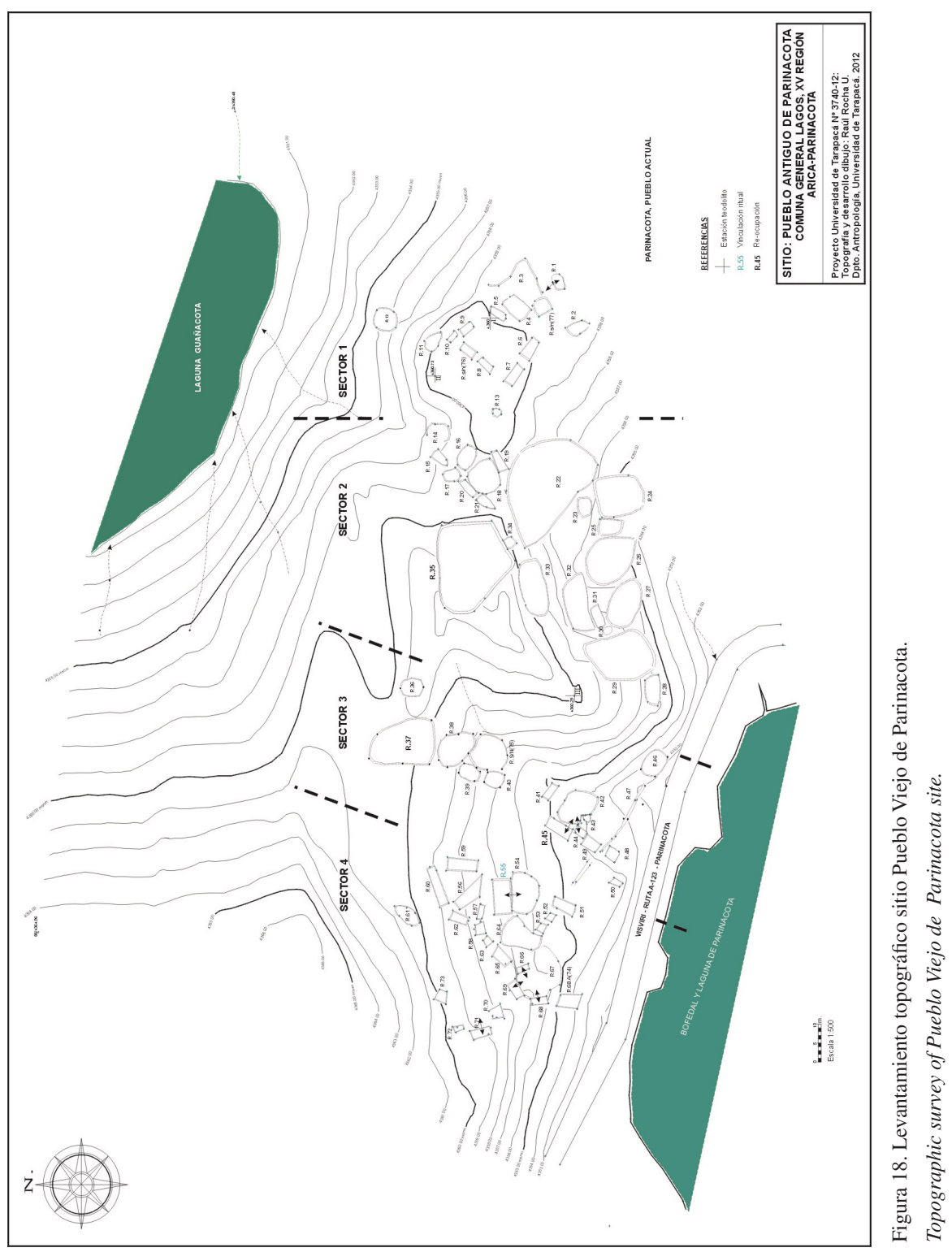




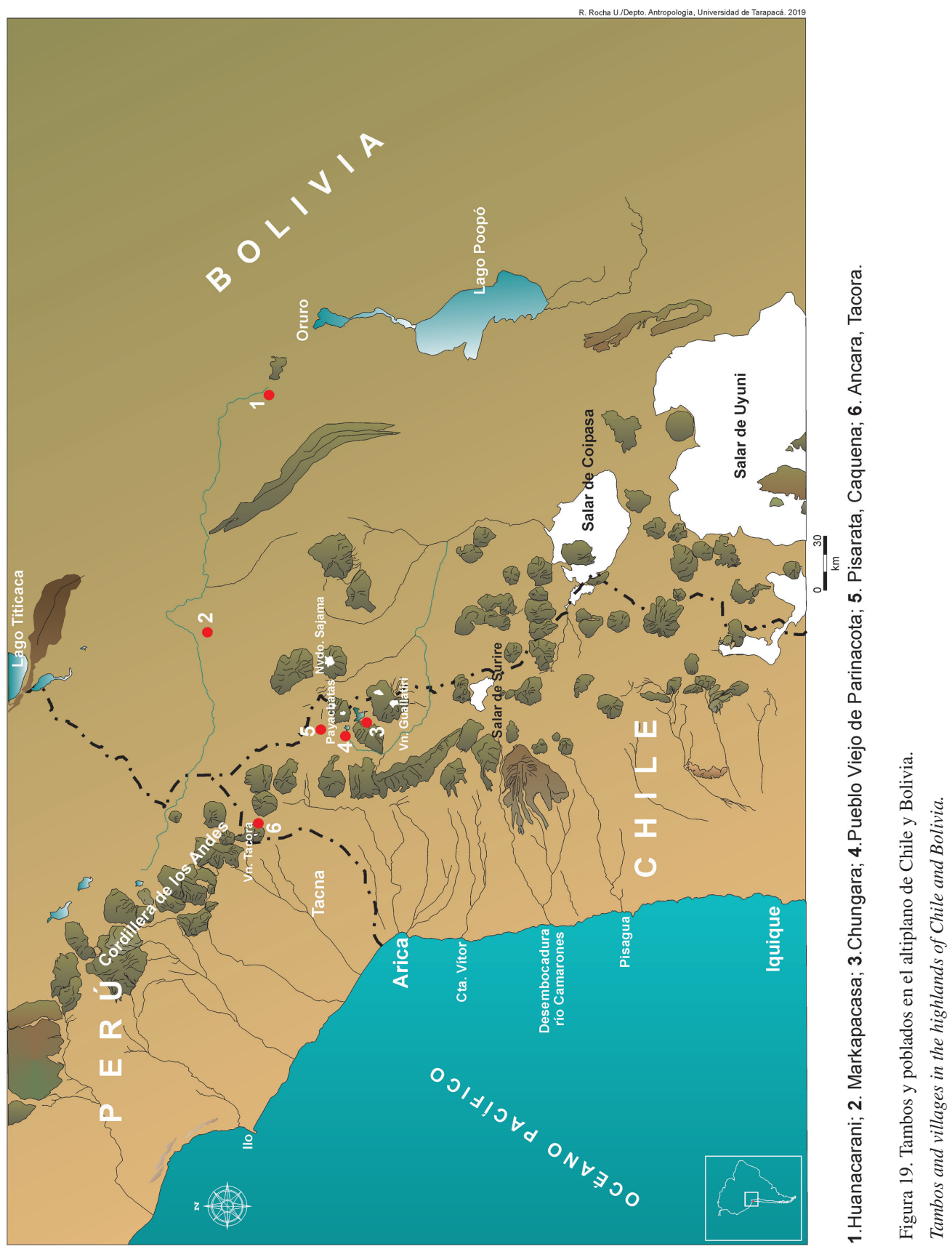




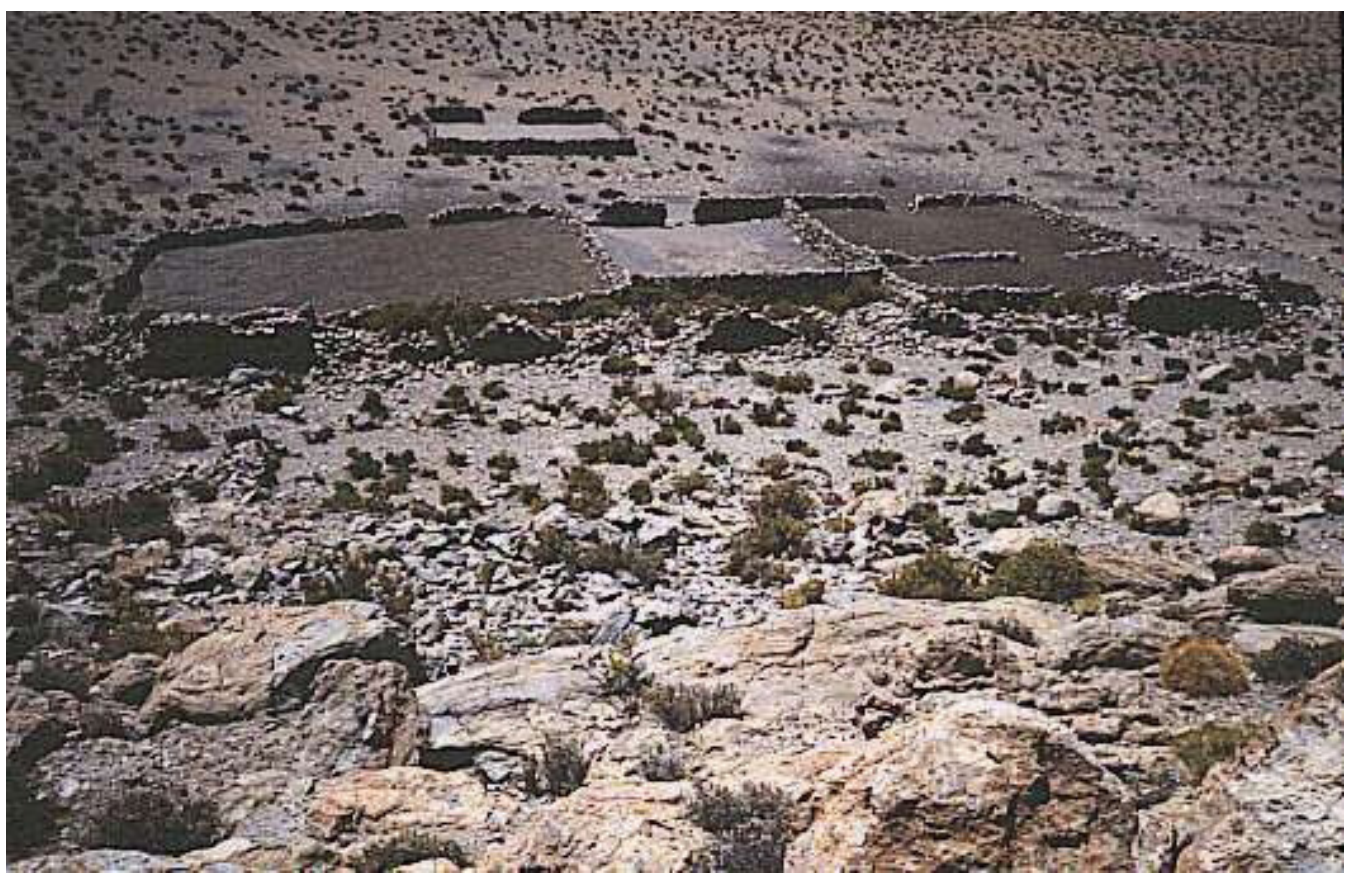

Figura 20. Vista general. Tambo de Ancara, Tacora, Altiplano provincia General Lagos, Chile.

General view. Ancara Tambo, Tacora, Altiplano, General Lagos province, Chile.

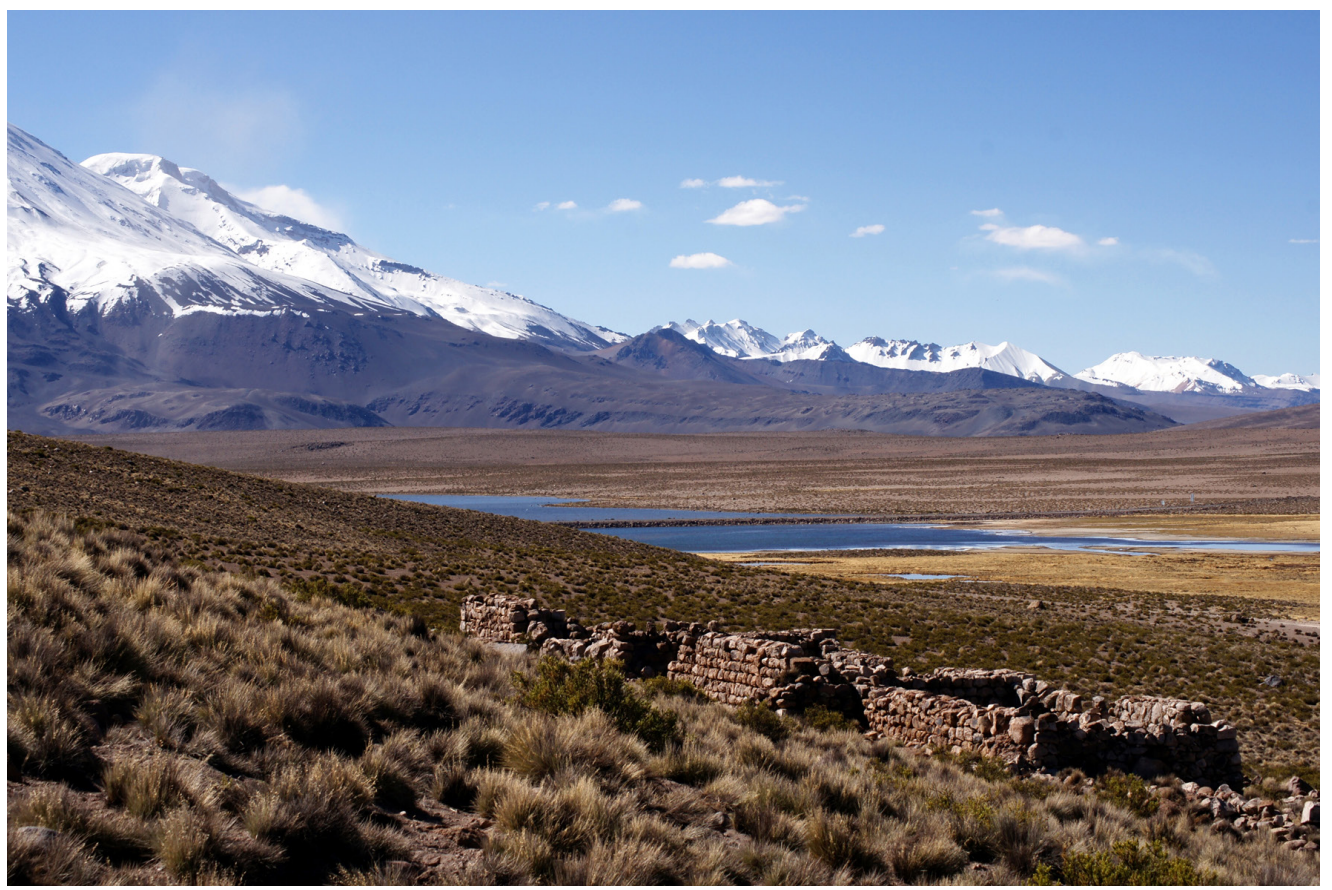

Figura 21. Vista general. Tambo Chungará, Localidad Chungará, altiplano, provincia General Lagos, Chile.

General view. Chungará Tambo, Chungará locality, Altiplano, General Lagos province, Chile. 


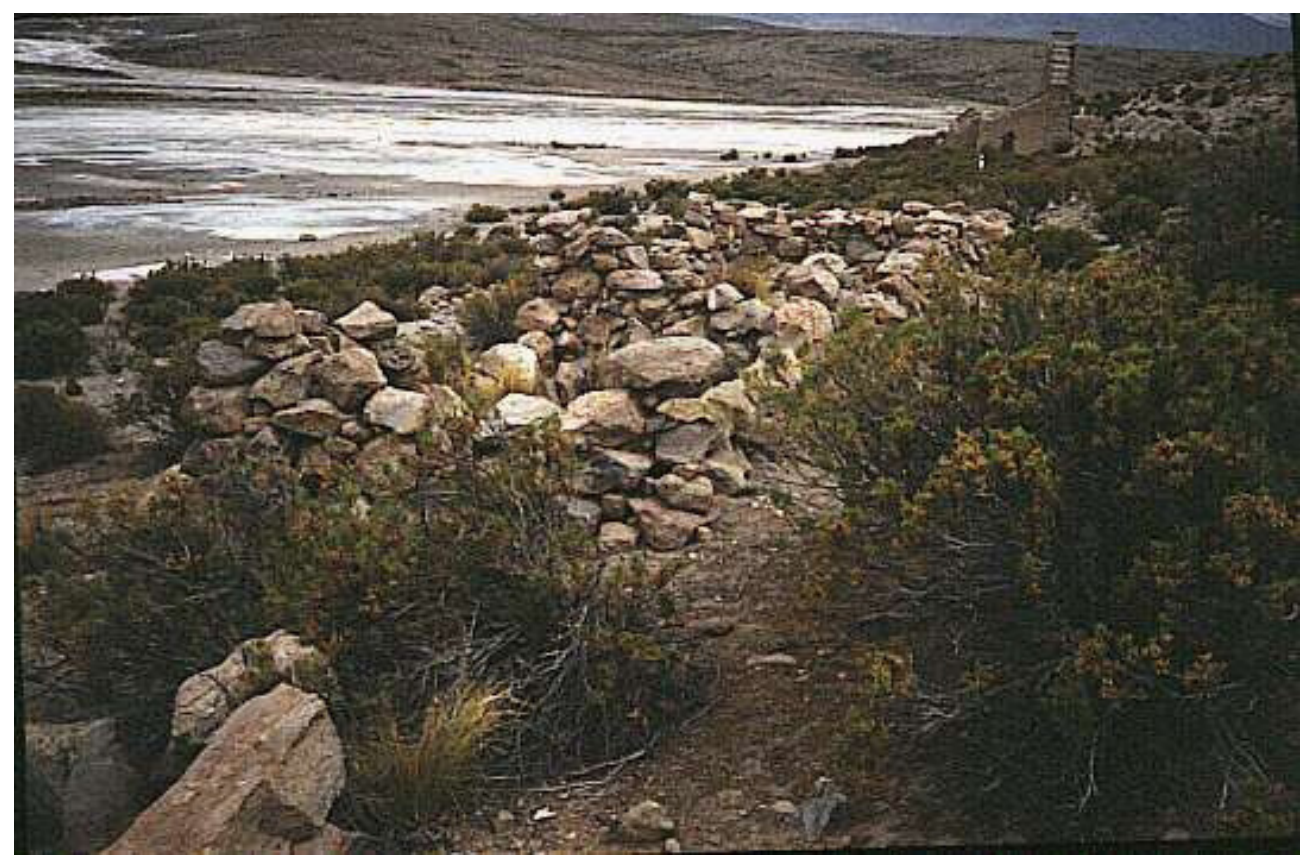

Figura 22. Vista General. Tambo de Pisarata, Caquena, Altiplano provincia General Lagos, Chile.

General view. Pisarata Tambo, Caquena, Altiplano General Lagos province, Chile.

fundacional local del pueblo, en este contexto y habiendo una estrecha relación en cuanto a la ubicación y orientación de las casas en el poblado Pueblo Viejo de Parinacota, los Payachatas pudieron haber sido la deidad fundacional mítica de los pobladores prehispánicos de Parinacota, constituyéndose por lo tanto en verdaderos cerros guardianes, ordenadores del paisaje ritual. Específicamente, la orientación de ventanas mirando a los nevados ayudan a entender esta estrecha relación simbólica entre pastores y nevados.

Otro espacio de connotación simbólica vinculado con la producción económica de los pobladores asentados en Pueblo Viejo de Parinacota lo constituye el bofedal ubicado en las inmediaciones del poblado. Según Jemio (2009), la relación entre el pastor de Carangas, el bofedal y sus pastizales es fuerte, considerando que es el espacio que provee los recursos para la sobrevivencia de los animales y las personas. La presencia de fragmentos de cerámicas de forma de escudillas con restos de comidas, sugieren que dichos restos alimenticios fueron parte de una phawa, comida que se prepara con fines ceremoniales e inspirada con la idea de fortalecer al bofedal para que proporcione buenos pastizales, base de una cadena alimentaria que involucra animales (camélidos) y al ser humano. Sin embargo, la existencia de estos bofedales está en íntima relación con la voluntad y poder de los nevados, que mantienen estos ecosistemas frágiles al proporcionarles el recurso hídrico permanente. Visto de esta manera, los nevados y el Bofedal de Parinacota en el contexto de la cosmovisión pudieron haber estado relacionados con los orígenes y los ancestros fundacionales vinculados a la población prehispánica que habitó Pueblo Viejo de Parinacota. Tal como sucede en la actualidad, los cerros o nevados están ligados con la fertilidad y la producción; por su parte los bofedales a través de sus vertientes son espacios de profunda ritualidad, ya que de ellos por ejemplo habría emergido el ganado. Esta trilogía de elementos formada por el agua, el ganado y el ser humano, que observamos etnográficamente en los pastores Carangas, la hemos podido rastrear a través de los indicadores arqueológicos y ceremoniales desde tiempos prehispánicos, como se expresa en Pueblo Viejo de Parinacota.

\section{La influencia Inca en la región de Carangas y Altiplano sur}

Según Bouysee-Cassagne (1987, 1988), durante el periodo Inca el territorio Carangas formaba parte del Collasuyu, y antes que los Incas estaba relacionado con la confederación Charca, compuestas por los Charcas, Chuis, Cara Cara y Chichas. . Wachtel (2001), por su parte, señala que los Carangas correspondían a una etnia de pastores, que conformaban uno de los señoríos Aymaras más grande del altiplano sur andino, que abarcaba hasta la costa del Pacífico, desde los valles de Lluta hasta la quebrada de Tarapacá́. Desde el punto 
de vista de los testimonios arqueológicos, al referirse al área de Carangas Michel (2000) señala que corresponde a una de las regiones con mayor presencia en cuanto a la infraestructura y ritualidad dejada como testimonios por parte del Tawantinsuyo. La alianza Inca-Carangas se refleja en la construcción de tambos, chullpas pintadas de variados colores, chullpas de piedra finamente talladas, templos cuadrangulares, ceques, santuarios de altura, redes de camino, etc., constituyéndose en evidencias de carácter administrativo y religioso del dominio Inca sobre los Carangas. Según Michel (2000); la alianza Inca-Carangas habría sido un punto de apoyo estratégico al imperio Tiwantinsuyo para su expansión, tanto en la guerra por el dominio Pacajes, como para la conquista de los valles de Cochabamba y el sur de Bolivia ${ }^{7}$. Entre las estrategias utilizadas por los Incas en su conquista sobre los Carangas, Morris y Covey (2006) y Villanueva (2015) señalan que a pesar de la corta duración de la hegemonía Inca en el altiplano sur, su influencia para relacionarse con las poblaciones de esta zona apuntó a la jerarquización de élites locales con el fin de administrar el tributo y el trabajo. Otra estrategia fue la de trasladar a tierras carangas poblaciones (Mitmaq) para fines productivos y de control, por ejemplo, la integración caminera, la ampliación y mejoramiento de la frontera agrícola. Para Michel (2000), ambas estrategias habrían permitido entre otras cosas la apropiación ritual del paisaje, el establecimiento de centros administrativos, el intercambio de conocimientos entre artesanos, que habría dado origen a estilos incas híbridos, o a la economía de bienes de prestigios y regalos para dirigentes locales.

Más hacia el altiplano sur, como en el caso de Pampa Aullagas, Oruro, Martínez (2011) señala que la ocupación Inca estuvo orientada al dominio territorial, poblacional y extracción de recursos para beneficio directo del imperio y su posterior redistribución a las poblaciones locales. $\mathrm{Su}$ objetivo fue ejercer un control efectivo sobre la población y la producción local, y para esto construyeron centros administrativos, recintos de almacenamientos y tambos. Lima (2008), por su parte, plantea que, en zonas alejadas, como el altiplano sur andino, el imperio habría establecido una estrategia que tenía como fin la centralización administrativa, promoviendo niveles de interculturalidad que generaron un nuevo panorama social, lo que produjo contactos multiétnicos ${ }^{8}$. Además, habría centralizado los poderes locales anulando la fuerza y decisión política e individual de los grupos, perdiéndose en el contexto local las identidades étnicas ${ }^{9}$. Esta estrategia conllevó a que las jefaturas de las organizaciones sociales al sur del Lago Poopo fueran parte del Incario a cambio del reconocimiento y oficialización de su autoridad. Lima (2008) señala que este hecho podría confirmar la realización de una alianza entre las elites locales y el imperio para su administración, como relatan los documentos etnohistóricos (Gisbert 1994).
Sejas (2010), al estudiar Tambo Viejo plantea que el Tawantinsuyo aparte de intervenir las redes de interacción, también lo hizo con la cerámica, con la introducción de nuevos tipos cerámicos y el consecuente control de su producción; sobre la función de Tambo Viejo, señala que se puede observar un cambio pasando de ser un lugar en el cual se realizaban actividades domésticas ligadas a la agricultura y en el cual se congregaba gente de diferentes grupos étnicos (Michel 2008). Esta forma de operar del Inca permitió, como lo señalan Earle y D'Altroy (1989), Uribe et al. (2002), y Williams y D'Altroy (1998), que se estableciera en la región una organización más vertical, perdiendo por lo tanto su independencia las poblaciones conquistadas.

En resumen, y de acuerdo con lo planteado por Lima (2008), de las estrategias asumidas por el Tawantinsuyu para lograr el control en las regiones de interés, arqueológicamente es posible reconocer tanto el control directo, la cual llama imposición forzosa, como el control indirecto, definido a través de las alianzas con las élites locales. En el caso de Pueblo Viejo de Parinacota, el análisis arquitectónico indicaría que las estructuras Inca fueron construidas con el consentimiento y trabajo de la gente local.

\section{La vinculación del Inca con el poblado Pueblo Viejo de Parinacota}

La presencia Inca, según los fechados obtenidos (ca. 1440 DC-1510 DC), habría ejercido el control de este poblado utilizando tal vez la estrategia de búsqueda de consenso con las autoridades locales, cuya representación estaba en manos de las poblaciones Caranga, que tenían presencia territorial en la puna desde a lo menos 300 años antes, según los antecedentes arrojados por los estudios de cerámica y arquitectura local (Muñoz 1996). El objetivo que los habría llevado a tener presencia en el asentamiento obedeció a ejercer el control de los bofedales y comunicaciones hacia los valles serranos y costeros del Pacífico. El Bofedal de Parinacota fue un recurso importante para las sociedades locales y habría sido el eje de la articulación socioeconómica en el lugar.

La construcción de tambos en distintos lugares donde se hallan bofedales explicaría la función de estos como centros de control de la producción ganadera, además de servir de albergue a caravanas que se desplazaban por el altiplano. Las evidencias de restos de lana, cueros y huesos de camélidos apoyan esta hipótesis. Por otro lado, la presencia de una diversificada red de senderos (rutas) que penetran (o se dirigen) desde el altiplano peruano-boliviano hacia el extremo norte de Chile, evidencia la existencia de una organizada red caminera por la que se movilizaron poblaciones con 
el propósito de intercambiar productos y bienes entre distintos pisos ecológicos de la vertiente occidental. Este intercambio generado por redes de caravanas que transitaban por los distintos pisos ecológicos pudo haber sido administrado por el Inca con el objetivo de obtener recursos para el mantenimiento del Estado. De tal manera, la instalación de tambos, ushño y kallankas como vemos en el poblado Viejo de Parinacota pudieron servir para que se instalaran los representantes del incanato, quienes posiblemente controlaron la producción ganadera con el propósito de mantener las relaciones de reciprocidad y redistribución entre el poder estatal, señoríos locales y comunidades circundantes.

En Pueblo Viejo de Parinacota los recintos arquitectónicos relacionados con la ocupación Inca se ubican en el espacio central del asentamiento, de tal manera que ocupa el mismo espacio residencial de las poblaciones locales vinculadas con el señorío Caranga. Este antecedente es de mucha importancia para entender cómo el estado Inca se relacionó con las poblaciones locales a partir de la reutilización de las áreas de ocupación estratégicas como fue el área residencial. Esta nueva forma de concebir el espacio de asentamiento donde se habría dado un área de convergencia de poblaciones venidas de distintos poblados de la puna, a raíz de la presencia inca, habría dado origen a un fuerte intercambio económico y fortalecimiento de las relaciones sociales, entre ellas la del parentesco. De tal manera que, con la influencia inca, el poblado Pueblo Viejo de Parinacota pasó a constituirse en un centro administrativo a nivel local, siendo parte de una organización sociopolítica que tuvo el dominio de enclaves productivos en las cabeceras de valles como Socoroma y Belén (Tocoroma).

Agradecimientos: Este artículo es producto de la investigación desarrollada en el marco del proyecto UTA 3736-18. Se agradece la colaboración en la confección del material fotográfico del Sr. José Raúl Rocha, encargado de la Oficina de Catalogación del Departamento de Antropología de la Universidad de Tarapacá. A los evaluadores del manuscrito, quienes con sus acertadas observaciones ayudaron a mejorar las ideas planteadas en el texto.

\section{Referencias Citadas}

Abercrombie, T. 2006. Caminos de la Memoria y el Poder. Institut français d'études andines, Instituto de Estudios Bolivianos-IEB, Cooperación ASDI-SAREC, La Paz.

Anschuetz, K., R. Wilshusen y Ch. Scheik 2001. An Archaeology of Landscape: Perspectives and directions. Journal of Archaeological Research 9:157-211.

Ashmore, W. 2010. Sacred Landscapes, Political Spaces. En VI Coloquio Pedro Bosch Gimpera. Lugar, Espacio y Paisaje en Arqueología: Mesoamérica y Otras Áreas Culturales, editado por E. Ortiz Diaz, pp. 297-322. Instituto de Investigaciones Antropológicas, UNAM, México DF.

Bouysse-Cassagne, T. 1987 La Identidad Aymara: Aproximación Histórica (Siglo XV y siglo XVI). Hisbol - IFEA, La Paz.

Bouysse-Cassagne, T. 1988. Lluvias y Ceniza: Dos Pachacuti en la Historia. Hisbol, La Paz.

Bouysse-Cassagne, T. y J. Chacama 2012. Partición colonial del territorio, cultos funerarios y memoria ancestral en Carangas y pre cordillera de Arica (siglos XVI-XVII). Chungara Revista de Antropología Chilena 44 (4):669-689.

Catacora, H., M. Clavijo, S. Fernández, P. Lima, F. Michel y M. Michel 2002. Una aproximación histórico-espacial a la relación hombre-medio ambiente en la cuenca del Poopó: el caso de Quillacas. En Diagnóstico de los Recursos Naturales y Culturales de los Lagos Poopó y UruUru, Oruro-Bolivia. Para su Nominación como Sitio Ramsar, editado por O. Rocha, pp. 137-151. Widlife Conservation Society, La Paz.

Choque, C. e I. Muñoz 2016. El Camino Real de La Plata. Circulación de mercancías e interacciones culturales en los valles y altos de Arica (Siglos XVI al XVIII). Historia 49 (1):57-86.

Condarco, C., E. Huarachi y M. Vargas 2002. Tras las Huellas del Tambo Real de Paria. Dirección de Posgrado e Investigación
Científica, Universidad Técnica de Oruro, Centro de Ecología y Pueblos Andinos y Programa de Investigación Estratégica en Bolivia, La Paz.

Cruz, P. 2007. Qaraqara e Inkas: el rostro indígena de Potosí. Estrategias de poder y supervivencia durante los siglos XV-XVI. Chachapuma 2:29-40.

Dauelsberg, P. 1983. Investigaciones arqueológicas en la sierra de Arica, sector Belén. Chungara Revista de Antropología Chilena 11:63-83.

Dauelsberg P. 1972/73. La Cerámica de Arica y su situación cronológica. Chungara Revista de Antropología Chilena 1-2:17-24.

Duffait, E. 2012. Vías prehispánicas y culto de los muertos en el norte chileno (Arica-Tarapacá) durante el periodo Intermedio Tardío y el Horizonte Tardío (ca. 1.000-1.532 d.C.). Chungara Revista de Antropología Chilena 44 (4):621-63.

Durston, A. y J. Hidalgo 1997. La presencia andina en los valles de Arica, siglos XVI-XVIII: Casos de regeneración colonial de estructuras archipielágicas. Chungara Revista de Antropología Chilena 2 9(2):249-273.

Earle, T.K. y T. D'Altroy 1989. The political economy of the Inka Empire: the archaeology of power and finance. En Archaeological Thought in America, editado por C.C. Lamberg-Karlovsky, pp. 183-204. Cambridge University Press, Cambridge.

Gisbert, T. 1994. El señorío de los Carangas y los chullpares del río Lauca. Revista Andina 2: 427-480.

Gisbert, T. 2008. La Iglesia de Curahuara de Carangas. Universidad Católica San Pablo, La Paz.

Jemio, L. 2009 Relatos de Montaña como Articuladores del Pensamientos del Pueblo de Sajama y del Pueblo de San José de Cala del Departamento de Oruro. Colección Saberes Andinos. Instituto de Estudios Boliviano (IEB), La Paz. 
Kesselli, R. y M. Pärsinnen 2005. Identidad étnica y muerte: torres funerarias (chullpas) como símbolos de poder étnico en el altiplano boliviano de Pakasa (1250-1600 d.C.). Bulletin de l'Institut Français d'Études Andines 34 (3):379-410.

Lecoq, P. 1997 Patrón de asentamiento, estilos cerámicos y grupos étnicos: el ejemplo de la región intersalar de Bolivia. En Saberes y Memorias en los Andes, editado por T. BouysseCassagne, pp. 59-89. CREDAL - IFEA, Lima.

Lima, M. 2002-2005. ¿Por la alianza o por la fuerza? Establecimiento del Incario al sur del lago Poopó, la relación del imperio con las poblaciones locales. Xama 15-18:161-175.

Lima, M. 2008. Interculturalidad como estrategia de control político: la relación de los inkas con los grupos locales del sur del lago Poopo. En Arqueología de las Tierras Altas, Valles Interandinos y Tierras Bajas de Bolivia: Memorias del I Congreso de Arqueología Boliviana, editado por C. Rivera Casanovas, pp. 131-144. UMSAPIEB, La Paz.

Lima, M. 2012. Caranguillas: ¿la capital pre-inka de los Carangas? Re-estructuración de la perspectiva territorial a partir de la presencia de los Inkas. En Turco Marka. Hombres, Dioses y Paisaje en la Historia de un Pueblo Orureño, editado X. Medinaceli, pp. 49-74. Instituto de Estudios Boliviano, La Paz.

Lima, P. y B. González 2014 Estudios binacionales entre Chile y Bolivia: investigaciones sobre el pasado precolombino y apuntes de la realidad actual de los Carangas. Estudios Sociales del NOA 14:109-127.

Martínez, A. 2011. El tambo de San Miguel de Uruquilla: Un centro de producción de quínoa durante el periodo Incaico. Pampa Aullagas-Oruro. Anales de la XXIV Reunión Anual de Etnología. Tomo, pp. 217-232. MUSEF, La Paz.

Martínez, J.L. 1995. Autoridades en los Andes. Los Atributos del Señor. Pontificia Universidad Católica del Perú, Lima.

Medinaceli, X. 2010. Sariri: Los Llameros y la Construcción de la Sociedad Colonial. Instituto Francés de Estudios Andinos (IFEA)- Plural Editores- ASDI- Instituto de Estudios Bolivianos (EB), La Paz.

Medinaceli, X. 2014. Los Inkas y las "naciones" del Collasuyu frente a la invasión española. En Ocupación Inka y Dinámicas Regionales en los Andes (Siglos XV-XVII), editado por C. Rivera Casanovas, pp. 267-286. IFEA / Plural Editores, La Paz.

Michel, M. 1996. Contexto histórico-sociocultural de la Unidad de Conservación. En Estudio de Manejo Integral del Área Protegida del Parque Nacional Sajama, editado por C. Miranda, pp. 54-128. SERNAP, Oruro.

Michel, M. 1999. Arqueología. En Diagnóstico Participativo del Parque nacional y Área de Manejo Integrado Cotapata, editado por P. Ergueta y A. García, pp. 81-114. TROPICO, Subcentrales de Pacallo y Chucura, La Paz.

Michel, M. 2000. El Señorío Prehispánico de los Carangas. Tesis de Diplomado Superior en derecho de los pueblos Indígenas. Universidad de la Cordillera, La Paz.

Michel, M. 2008. Patrones de Asentamiento Precolombino del Altiplano Boliviano Lugares Centrales de la Región de Quillacas. Departamento de Oruro, Bolivia. Department of Archaeology and Ancient History, Uppsala University, Uppsala.

Molina, R. y R. Barragán 1987. De los Señoríos a las Comunidades, Historia Étnica de los Quillacas. Christian Children's Fund (CCF), La Paz.

Montes de Oca, I. 1997. Geografía y Recursos Naturales de Bolivia. Banco Central de Bolivia, La Paz.
Morris, G. y A. Covey 2006. The Management of Scale or the Creation of scale: administrative processes in Two Inka Provinces. En Intermediate Elites in Pre-Columbian States and Empires, editado por C. Elson y A. Covey, pp 136-153. University of Arizona Press, Tucson.

Muñoz, I. 1996. Asentamientos e interrelaciones culturales: Un aproximación al proceso prehispánico tardío en la sierra de Arica. Tiwantinsuyu 2:44-58.

Muñoz, I. y J. Chacama 2006. Complejidad Social en las Alturas de Arica: Territorio, Etnicidad y Vinculación con el Estado Inca. Ediciones Universidad de Tarapacá, Arica.

Muñoz, I., J. Chacama, G. Espinosa y L. Briones 1987. La ocupación prehispánica tardía de Zapahuira y su vinculación a la organización económica y social Inca. Chungara Revista de Antropología Chilena 18:67-89.

Muñoz, I., J. Rocha y M. Santos 2011-2016. El Inca a los pies de los Payachatas: Descripción del sistema constructivo, ocupación del espacio y alfarería en el poblado Pueblo Viejo de Parinacota, extremo norte de Chile. Xama 24-29:59-80.

Murra, J. 1975. Formaciones Económicas y Políticas del Mundo Andino. Instituto de Estudios Peruanos, Lima.

Parssinen, M. y A. Siiriäinen 1997. Inka-style ceramics and their chronological relationship to the Inka expansion in the southern Lake Titicaca area (Bolivia). Latin American Antiquity 8:255-271.

Rivera, C. 2014. Estrategias de control imperial, movimientos poblacionales y dinámicas regionales durante el período Tardío en la región de San Lucas, Chuquisaca. En Ocupación Inka y Dinámicas Regionales en los Andes (Siglos XV-XVII), editado por C. Rivera Casanovas, pp. 67-98. IFEA/Plural editores, La Paz.

Rivière, G. 1982. Sabaya: Structures Socio-economiques et Representations Symboliques dans les Carangas - Bolivie. Thèse de 3ème cycle en ethnologie, École des Hautes Études en Sciences Sociales, París.

Rivière, G. 1988. Dualismo y cuatripartición en Carangas. Revista del Museo Nacional de Etnografía y Folklore 1 (1-2):67-121.

Romero, A. 2005. Organización Social y Economía Política en la Prehistoria Tardía de los Valles de Arica (1.100-1.530 d.C.). Memoria para optar al título de Arqueólogo. Departamento de Antropología, Facultad de Ciencias Sociales, Universidad de Chile, Santiago.

Saignes T. 1986. En Busca del Poblamiento Étnico de los Andes Bolivianos (Siglos XV y XVI). Museo Nacional de Etnografía y Folklore, La Paz.

Saintenoy, T., R. Ajata, A. Romero y M. Sepúlveda 2017. Arqueología del territorio aldeano prehispánico tardío en los Altos de Arica: aportes de la fotointerpretación satelital para el estudio regional de la cuenca alta de Azapa. Estudios Atacameños Arqueología y Antropología Surandinas 54: 85-110.

Santoro, C., A. Romero, V. Standen y A. Torres 2004. Continuidad y cambio en las comunidades locales, períodos Intermedio Tardío y Tardío, Valles Occidentales del Área Centro Sur Andina. Chungara Revista de Antropología Chilena 36 (Suplemento Especial 1): 235-247.

Schiappacasse, V. y H.F. Niemeyer 1999. Continuidad y cambio cultural en el poblado actual colonial e inca de Pachica, quebrada de Camarones. Chungara Revista de Antropología Chilena 29 (2):209-248.

Sejas, A. 2010. Cambios en las Redes de Interacción de las Poblaciones en el Sitio Tambo Viejo durante el Período Tardio: Una Visión a Través de la Cerámica de Oruro, Bolivia. Memoria para optar al título de Arqueóloga, Departamento de Antropología, Facultad de Ciencias Sociales, Universidad de Chile, Santiago. 
Thomas J. 2010. Understanding past landscapes: experience, memory and materiality. VI Coloquio Pedro Bosch Gimpera. Lugar, Espacio y Paisaje en Arqueología: Mesoamérica y otras Áreas Culturales, editado por E. Ortiz Díaz, pp. 27-46. Instituto de Investigaciones Antropológicas, México DF.

Tilley, C. 2008. Phenomenological approaches to landscape archaeology. En Handbook of Landscape Archaeology, editado por B. David y J. Thomas, pp. 271-276. Left Coast Press, Walnut Creek

Torrez, D.R. 2019. Complementariedad y Conflicto en los Sitios Arqueológicos de Altura en la Montaña Sajama durante el Periodo Intermedio Tardio (1000 - 1450 D.C.). Tesis de Licenciatura. Facultad de Ciencias Sociales, carreras de Arqueología y Antropología, Universidad Mayor de San Andrés, La Paz.

Uribe, M., L. Adán y C. Agüero 2002. El dominio del Inka, identidad local y complejidad social en las tierras altas del desierto de Atacama, Norte Grande de Chile (1450-1541 d.C.). Boletín de Arqueología PUCP 6:301-336.
Van Buren, M y B. Weaver 2014. Exigir una diferencia: el uso estratégico de la cerámica Inka Provincial en el período Colonial Temprano. En Ocupación Inka y Dinámicas Regionales en los Andes (Siglos XV-XVII), editado por C. Rivera Casanovas, pp. 245-266. IFEA / Plural editores, La Paz.

Villanueva, J. 2015. El Ceremonial Chullpario y la Construcción de Comunidades Humanas en el Altiplano de Carangas, Bolivia, durante el Período Intermedio Tardio (ap. 1100-1450 d.C.). Tesis doctoral, Programa de Postgrado en Antropología, Universidad de Tarapacá - Universidad Católica del Norte, Arica.

Wachtel, N. 2001. El Regreso de los Antepasados. Los Indios Urus de Bolivia del Siglo XX al XVI, Ensayo de Historia Regresiva. Fondo de Cultura Económica, México DF.

Williams, V. y T. D'Altroy 1998. Al sur del Tawantinsuyu: un dominio selectivamente intensivo. Tawantinsuyu 5:170-178.

\section{Notas}

${ }^{1}$ Medinaceli (2010:133) plantea que el señorío de Carangas estuvo dividido en tres parcialidades: Hanansaya, Urinsaya y Hatun Carangas, siendo Hatun Carangas la parcialidad más prestigiosa en tiempos preincaicos, la que habría estado formada por los pueblos de Sabaya, Chuquitoca y Turco, sector donde existen numerosas chullpas funerarias y poblados. Por su cercanía, territorio de ocupación e indicadores culturales, sugerimos que el asentamiento Pueblo Viejo de Parinacota habría estado vinculado a esta parcialidad.

${ }^{2}$ Según Muñoz y Chacama (2006) es común en los asentamientos del periodo Tardío en los valles altos del norte de Chile hallar recintos de forma circular, oval y rectangular insertos en un mismo espacio habitacional, lo que sugiere una combinación de patrones arquitectónicos de carácter local y foráneo (Inca).

${ }^{3}$ Según Michel (2000:62) esta cerámica se caracteriza en su cara exterior por "formas geométricas de espirales, líneas onduladas, asteriscos, medios círculos, rellenos con líneas onduladas, círculos superpuestos, tramas de enrejados. Las partes internas comúnmente presentan decoración de líneas simples que bajan del labio a la base produciendo divisiones cuatripartitas o diversas, en otros casos se observan líneas con triángulos, círculos, medios círculos superpuestos sobre la misma línea. Otros casos poseen composiciones lineales de escaleras, formas de ramas, líneas horizontales simples acompañadas de líneas onduladas y círculos. Es común el diseño de llamas dibujada de forma tosca y gruesa".

${ }^{4}$ Los poblados de la precordillera y sierra de Arica son mayores en términos de recintos llegando incluso alcanzar 500 a 700 estructuras como Huaihuarani y Saxamar. Las formas son circulares y oval; presentan algunos de ellos muros perimetrales, un espacio característico son las plazas, algunas de ellas vinculadas a los cementerios. Las distancias entre ellos van de 10 a $30 \mathrm{Km}$ y están comunicados por senderos.

${ }^{5}$ Varias son las edificaciones arquitectónicas dejadas como testimonio por las poblaciones Carangas prehispánicas. Según Gisbert (1994, 2008), las chullpas de barro alcanzaron un número elevado (97); algunas como Macaya, Jiskha Molle Pucara, Jankho Vinto, Wila Kollu, Churo Patilla, Jallu Chullpas, Chiar Kollu, por sus diseños se pueden agrupar en diez tipos: pintadas de rojo, frisos de equis, rombos ligados entre sí y dispuestos verticalmente, ajedrezado rojo y blanco en las tres caras, ajedrezado rojo y blanco con una línea horizontal en la parte media, ajedrezado rojo y blanco con diseños a manera de ojos, rombos concéntricos rojo sobre blanco y viceversa, sin pintura pero con ventana alta decorada en rojo, blanco y verde, ajedrezado rojo y blanco con greca horizontal en la parte media, rombos continuos. ${ }^{6}$ Según Lima (2002-2005), tomando como referencia a Bouysse-Cassagne (1987, 1988), las organizaciones más importantes del altiplano Occidental se encuentran en los Lupacas (Murra 1975), los Pacajes (Parssinen y Siiriäinen 1997), los Carangas (Michel 1999; Rivière 1982, 1988; Villanueva 2015), los Quillacas (Abercrombie 2006; Molina y Barragán 1987) y los Lipez (Martínez 1995).

7 Algunos sitios representativos de la influencia Inca corresponden a los tambos Inca Paria y Anocariri, Sevaruyo, Chuquicota, poblados de Turko, Sajama, Chullpas de colores como Macaya, Tarachita, Wila Kollu, Janko Chullpa, Pukara, Wila Chullpa, Jallulchullpa, Chiarcollo, Jilarata y Volcan Quemado (Michel 2000).

${ }^{8}$ Esta forma de centralización fue descrita por Michel (2008) para el Horizonte Medio, en Oruro.

9 Según Medinaceli (2014) las autoridades locales perviven con poder y representación hasta la Colonia. 